Check for updates

Cite this: RSC Adv., 2019, 9, 37830

Received 19th August 2019

Accepted 18th October 2019

DOI: 10.1039/c9ra06494j

rsc.li/rsc-advances

\section{Counterion coupled (COCO) gemini surfactant capped Ag/Au alloy and Ag@Au core-shell nanoparticles for cancer therapy $\dagger$}

\author{
A. Mohammed Siddiq, ${ }^{a}$ Ramar Thangam, id $t^{b}$ Balaraman Madhan ${ }^{\text {bc }}$ \\ and Md. Sayem Alam iD *ac
}

Hybrid silver (Ag) - gold ( $\mathrm{Au}$ ) nanoparticles (NPs) with different sizes and compositions were synthesized. Ag/ Au alloy and Ag aAu core-shell type NPs were prepared from Ag and Au with various ratios using the COCO gemini surfactant, 1,6-bis (N,N-hexadecyldimethylammonium) adipate (COCOGS), 16-6-16 as a stabilizer. The formation of the $\mathrm{Ag} / \mathrm{Au}$ alloy and $\mathrm{Ag} @ \mathrm{Au}$ core-shell was confirmed by UV-visible absorption spectroscopy, high-resolution transmission electron microscopy (HRTEM), energy-dispersive X-ray spectroscopy (EDX) and selected area electron diffraction (SAED) patterns. Depending on the composition of the Ag/Au alloy NPs, the $\lambda_{\text {max }}$ values varied from $408 \mathrm{~nm}$ to $525 \mathrm{~nm}$. FTIR measurements were used to evaluate the adsorption of the COCO gemini surfactant (16-6-16) on the Ag/Au alloy and Ag@Au core-shell surface. In this present work, we study how to achieve the stability and activity of the COCO gemini surfactant (16-6-16) capped Ag/Au alloy and Ag@Au core-shell NPs for developing novel anti-cancer agents by evaluating their potentials in the Hep-2 cell line model. Thus the developed coreshell NPs were possibly involved in inducing cytotoxicity followed by inhibition of cell proliferation to the cancer cells with apoptosis induction. The developed core-shell NPs might serve as highly applicable agents in the development of next-generation cancer chemotherapeutic agents.

\section{Introduction}

Hybrid nanoparticles (NPs) have attracted serious interest due to their entrancing electronic, optical, catalytic and sensing properties. $^{1-6}$ The properties of monometallic noble NPs with different morphologies, sizes, and shapes have been widely investigated. $^{7-10}$ However, the properties are not up to the requirement of various applications, and therefore, research has started focusing on bimetallic NPs. This class of materials generally consists of some one of a kind physiochemical and surface attributes because of the combinational communications between two metallic electronic states which are not quite

\footnotetext{
${ }^{a}$ Polymer Science and Technology, Council of Scientific and Industrial Research (CSIR) - Central Leather Research Institute (CLRI), India. E-mail: sayemalam@gmail.com; sayem@clri.res.in; Tel: +91-44-24437106

${ }^{b}$ Centre for Academic \& Research Excellence (CARE), Council of Scientific and Industrial Research (CSIR) - Central Leather Research Institute (CLRI), Adyar, Chennai 600 020, India

${ }^{c}$ Academy of Scientific and Innovative Research (AcSIR), Council of Scientific and Industrial Research (CSIR) - Central Leather Research Institute (CLRI), New Delhi110001, India

$\dagger$ Electronic supplementary information (ESI) available. See DOI: 10.1039/c9ra06494j

† Current address: Institute for Molecular Imaging \& Theranostics (iMIT), Department of Nuclear Medicine, Chonnam National University Medical School, Hwasun Hospital, South Korea.
}

the same as the individual metals. Bimetallic NPs can have various structures including nanowires, dendrites, alloys, coreshells, etc. ${ }^{11-14}$ Among these, bimetallic core-shell nanostructures of gold and silver have attracted much enthusiasm for their plasmonic, catalytic, ${ }^{15,16}$ sensor, ${ }^{17-22}$ bioimaging, ${ }^{23}$ and photothermal therapy (PTT) applications. ${ }^{24-26}$

In particular, cancer treatment using bimetallic nanostructures is of great research interest among the scientific community due to their exceptional physicochemical properties. The fast advancement of human malignant growths is identified with the avoidance of the body's invulnerable reconnaissance systems through cancer cells, which are seen by the discharge of immunosuppressive factors that alter the host safe reaction. By and by, accessible chemotherapeutic medications additionally stifle the safe framework, increasing the likelihood of diseased patients to experience additional infections. ${ }^{27}$ In such a manner, there is a critical neglected need for novel pharmaceutical compounds with tumor selectivity and specificity with minimal symptoms. Concerning this, the nanomaterials-based drug seems to be an efficient entity. Among different bimetallic alloy NPs, Ag-Au NPs have attracted broad research as of late for biomedical applications because of their tunable physical, chemical and biological properties, and simple engineered methodology. ${ }^{28,29}$ Also, while monometallic $\mathrm{Ag}$ and $\mathrm{Au}$ NPs have generally constant optical properties because of the surface plasmon reaction (SPR), the SPR 
properties of Ag/Au alloy NPs are ceaselessly tunable in light of the likelihood of composition changes. ${ }^{30}$

Silver NPs are commonly viewed as more poisonous than AuNPs, with a few examinations demonstrating that cell presentation to AgNPs instigated critical cytotoxicity. ${ }^{31-34}$ Conversely, Yen et al. chose a lower cytotoxicity of AgNPs than that of the AuNPs and credited this refinement to the surface charges between NPs, which can clarify the inconsistency with different investigations identified with AgNPs cytotoxicity. ${ }^{35}$ However, the improvement of disease cells can dodge the cytotoxicity of traditional chemotherapeutics as well as this newer molecularly focused on therapeutics. Nanoparticles, by using both passive and active targeting strategies, can upgrade the intracellular convergence of medications in malignant growth cells while avoiding toxicity in normal cells. ${ }^{28}$ To successfully convey the medication to be focused on tumor tissue, core-shell nanoparticles must be able to stay in the circulatory system for an appropriate amount of time without being excreted. The destiny of infused nanoparticles is determined by altering their size and surface attributes. For instance, V. Grasmick et al. synthesised core-shell and alloy nanostructures composed of $\mathrm{Ag}-\mathrm{Au}$ (Ag30Au70, Ag50Au50, and Ag70Au30) using under potential deposition (UPD) to investigate the crystallographic surface constitution and the arrangement of the bimetallic NPs. On account of $\mathrm{Ag}-\mathrm{Au}$ being an alloy, UPD makes it conceivable to distinguish between a homogeneous alloy and a core-shell framework when joined with cyclic voltammetry. ${ }^{36} \mathrm{X}$. Sun et al. carried out a mechanistic study of the rational design of $\mathrm{Ag}-\mathrm{Au}$ bimetallic NPs in which the deposition of $\mathrm{Au}$ on colloidal $\mathrm{Ag}$ nanocubes via a galvanic replacement reaction plays a crucial role in the fabrication of novel functional nanomaterials. ${ }^{37}$ Besides, in terms of bioactivity, these alloy and core/shell nanostructures have many advantages. For instance, D. Tiedemann et al. investigated the role of $\mathrm{Ag}^{+}$ions' release toward toxicity on cumulus-oocyte buildings and spermatozoa utilizing BSA covered $\mathrm{Ag}, \mathrm{Au}$, and alloys of $\mathrm{Au}-\mathrm{Au}$ NPs and discovered that the $\mathrm{Ag}$ proportion determined the toxicity on cumulus-oocyte edifices. At the point when the Ag molar proportion was higher than half, negative consequences for porcine gametes were seen because of disintegrated $\mathrm{Ag}^{+}$ions. Therefore, it was clear that the compounding of Ag into an alloy was able to decrease the lethal impacts to a specific cutoff. ${ }^{29} \mathrm{~S}$. Grade $e t$ al. reported that alloying of Ag-Au NPs greatly assists in deactivating the toxicity effect of $\mathrm{Ag}^{+}$discharge regardless of whether there is core-shell dissemination, because of the presence of the homogeneous dissolution of $\mathrm{Ag}$ and $\mathrm{Au}$ in the nanostructure. ${ }^{28}$

However, the fundamental issue with Ag/Au alloy and Ag@Au core-shell NPs is related to the adequate strength of their scatterings permitting the anticipation of the accumulation. Consequently, this hinders the efficiency of the drug for cancer therapy. In this way, different polymers and surfactants ${ }^{36,37}$ are used to stabilize the NPs. Despite the fact that the dependability is viewed as a vital property of the Ag/Au alloy and Ag@Au core-shell NPs scatterings, there is as yet an absence of studies. Recently, much attention has been paid to the gemini surfactant as an efficient alternative stabilizing agent to produce noble metal NPs. This is principally attributable to its prevalent properties, for example, its lower basic micelle fixation (CMC), higher surface movement, and greater cost-effectiveness in comparison with conventional surfactants. ${ }^{38}$ It contains two hydrophilic heads and two hydrophobic groups. It has been accounted for that gemini surfactants can be utilized to prepare different gold nanostructures, including nanospheres, ${ }^{39,40}$ nanoribbons, ${ }^{41}$ and branched nanostructures. ${ }^{42}$ Another type of gemini surfactant is the counterion coupled gemini surfactant (COCOGS). In COCO gemini surfactant, two surfactant tails are bound through a geometrically wellcharacterized functional counterion. ${ }^{43-46}$ Unlike ionic surfactants (conventional just as gemini), COCO gemini surfactants are just feebly separated, i.e., they exist as dense zwitterions instead of by means of an isolated species. COCO gemini surfactants are found as stable microemulsions with large, clear interface regions. In this manner, COCO gemini surfactants are promising competitors in different applications, particularly in drug delivery. There are numerous reports where traditional surfactants are utilized as a capping agent. Notwithstanding, as far as we could possibly know, there are no reports of the COCO gemini surfactant being used in bimetallic NPs synthesis. Restricted research reports could be accessible in this specific zone of research. In this way, it is fundamental to comprehend the role of the COCO gemini surfactant on the synthesis of NPs. With this in view, the present examination plans to test the in vitro activity of AgNPs, AuNPs, Ag/ Au alloy, and Ag@Au core-shell NPs on Hep-2 cells.

\section{Experimental}

\subsection{Materials and methods}

The following chemicals were purchased and utilized with no further filtration: silver nitrate $(\geq 99.9 \%)$, gold(III) chloride $(\geq 99.9 \%)$, and sodium borohydride ( $\geq 99 \%)$, Sigma, USA. Potassium hydroxide (KOH) was used as received. The COCO gemini surfactant, 1,6-bis ( $N, N$-hexadecyltrimethylammonium) adipate (COCOGS), 16-6-16, was synthesized and purified. ${ }^{47}$ In all the experiments Milli-Q water is used. The specific conductivity of the Milli-Q water at $25{ }^{\circ} \mathrm{C}$ was $1-2 \mu \mathrm{S} \mathrm{cm}^{-1}$.

\subsection{Methods}

Synthesis of Au, Ag, Au@Ag core-shell and Au/Ag alloy NPs. For the synthesis of the AuNPs, $5 \mathrm{ml}$ of $\mathrm{AuCl}_{3}(2.5 \mathrm{mM})$ was added into $50 \mathrm{mM}$ COCOGS $(2.5 \mathrm{ml})$ under stirring for 10 minutes followed by $2.5 \mathrm{mM}(5 \mathrm{ml})$ of $\mathrm{NaBH}_{4}$, which was added drop-wise into the above solution at ice-cold conditions $\left(0^{\circ} \mathrm{C}\right)$. The shade of the solution turned to ruby red after the addition of $\mathrm{NaBH}_{4}$, which shows the formation of AuNPs. The solution was permitted to stir further for 45 minutes to deliver a stable solution. The hydrosol was matured for $24 \mathrm{~h}$ and after that centrifuged at $10000 \mathrm{rpm}$ for $5 \mathrm{~min}$.

Briefly, $\mathrm{AgNO}_{3} 20 \mathrm{mM} 2.5 \mathrm{ml}$, COCOGS $50 \mathrm{mM} 2.5 \mathrm{ml}$ and $1 \mathrm{ml} \mathrm{KOH} 20 \mathrm{mM} 1 \mathrm{ml}$ were added to $41.5 \mathrm{ml}$ water and the solution was stirred under $\mathrm{N}_{2}$ atmosphere for $30 \mathrm{~min}$. Freshly prepared $\mathrm{NaBH}_{4} 0.1 \mathrm{M} 2.5 \mathrm{ml}$ solution was added. Then it was allowed to stir for $1 \mathrm{~h}$ and matured for $48 \mathrm{~h}$. The synthesized AgNPs are denoted as Ag-1. Several different hydrosols containing AgNPs of various sizes were acquired by changing the 
composition of the reaction mixture $\left(\mathrm{AgNO}_{3}, \mathrm{COCOGS}, \mathrm{NaBH}_{4}\right.$ and $\mathrm{KOH}$ solution), and were denoted as Ag-2, Ag-3 Ag-4 and Ag5 (see Table S1 ESI $\dagger$ ). The hydrosol was matured for $24 \mathrm{~h}$ and afterward centrifuged at $10000 \mathrm{rpm}$ for $5 \mathrm{~min}$ to produce the $\mathrm{AgCl}$ precipitate.

Ag-1 was utilized to prepare Ag@Au core-shell NPs with various compositions. Ag-1 $20 \mathrm{ml}$ was refluxed at $100{ }^{\circ} \mathrm{C}$ and $1 \mathrm{mM} \mathrm{AuCl}_{3}$ solution was added to $\mathrm{Ag}-1$ under vigorous stirring, refluxed for $10 \mathrm{~min}$ and matured for $24 \mathrm{~h}$. The core-shell NPs obtained by adding 5.45, 6.15 and $4.44 \mathrm{ml}$ of $1 \mathrm{mM}$ of $\mathrm{AuCl}_{3}$ were denoted as Ag@Au-3, Ag@Au-4, and Ag@Au-5, respectively. Similarly, Ag@Au core-shell NPs with the same composition but with various sizes were prepared by $20 \mathrm{ml}$ of $(\mathrm{Ag}-2, \mathrm{Ag}$ $3, \mathrm{Ag}-4$ or Ag-5) and $4.44 \mathrm{ml}$ of $1 \mathrm{mM}$ of $\mathrm{AuCl}_{3}$. The core-shell NPs were prepared and denoted as Ag@Au-6, Ag@Au-7, and $\mathrm{Ag@Au-8,} \mathrm{respectively.}$

$\mathrm{Ag} / \mathrm{Au}$ alloy NPs were synthesized; briefly, $\mathrm{AgNO}_{3} 20 \mathrm{mM}$ $2.5 \mathrm{ml}, \mathrm{AuCl}_{3} 1 \mathrm{mM} 2.86 \mathrm{ml}$, COCO gemini surfactant $50 \mathrm{mM}$ $2.5 \mathrm{ml}$ and $\mathrm{KOH} 20 \mathrm{mM} 1 \mathrm{ml}$ were mixed with $41.5 \mathrm{ml}$ water and stirred for $10 \mathrm{~min}$. Freshly prepared $\mathrm{NaBH}_{4} 0.1 \mathrm{M} 2.5 \mathrm{ml}$ solution was added. Then it was allowed to stir for $1 \mathrm{~h}$ and matured for $48 \mathrm{~h}$. The alloy NPs obtained by adding 2.86 and $4.44 \mathrm{ml}$ of $1 \mathrm{mM}$ of $\mathrm{AuCl}_{3}$ were noted as $\mathrm{Ag} / \mathrm{Au}-1$ and $\mathrm{Ag} / \mathrm{Au}-2$, respectively.

\subsection{Characterization techniques}

UV-visible spectroscopy. The UV-visible absorption spectra measured with a UV-visible spectrophotometer, (Varian, model: Cary 100) were carried out for Ag-1, $\mathrm{Au}, \mathrm{Ag} / \mathrm{Au}$ alloy NPs and $\mathrm{Ag} @ A u$ core-shell NPs samples in the scan range of $200-800 \mathrm{~nm}$ and recorded at $25^{\circ} \mathrm{C}$.

X-ray diffraction analysis (XRD). The lyophilized powder of $\mathrm{Ag}-1, \mathrm{Au}, \mathrm{Ag} / \mathrm{Au}$ alloy NPs and Ag@Au core-shell NPs were subjected to X-ray diffraction analysis by a Rigaku Miniflex-II Desktop X-ray diffractometer at an operating voltage of $40 \mathrm{kV}$ and a current of $30 \mathrm{~mA}$ with $\mathrm{CuK} \alpha 1$ radiation (wavelength $=$ $1.54056 \AA$ ). The scanning was taken in the region of $2 \theta$ from $20^{\circ}$ to $80^{\circ}$. The size of the crystallites was calculated using the Scherrer equation. ${ }^{48}$

Inductively coupled plasma-optical emission spectrometry (ICP-OES). $50 \mathrm{mg}$ of the sample was added to a Teflon microwave digestion vessel and $1 \mathrm{ml}$ of ultrapure nitric acid was added to react for about 45 minutes using the Anton Paar microwave digestion unit. After that, the sample was made up to a $50 \mathrm{ml}$ standard measuring flask. The standard calibration solution was prepared for $0.05 \mu \mathrm{g} \mathrm{ml}^{-1}$ to $10 \mu \mathrm{g} \mathrm{ml}^{-1}$ by using ultrapure nitric acid and also a blank. The Agilent ICP-OES 5100 VDV instrument was used with the following operation conditions: an RF power of $1.2 \mathrm{~kW}$, a plasma gas flow rate of 12 $1 \mathrm{~min}^{-1}$, and a nebulizer gas flow rate of $0.701 \mathrm{~min}^{-1}$. The samples were introduced into the plasma using a nebulizer and spray chamber for the analysis of the elements, namely silver $(328.068 \mathrm{~nm})$ and gold $(242.794 \mathrm{~nm})$.

Dynamic light scattering (DLS) and zeta potential. The zeta potential and hydrodynamic diameter of $\mathrm{Ag}-1$ to $5, \mathrm{Au}, \mathrm{Ag} / \mathrm{Au}$ alloy NPs and Ag@Au core-shell NPs were analyzed using Malvern Zetasizer version 6.2.
High-resolution transmission electron microscopy (HRTEM). For this, the Ag-1, Au, Ag/Au alloy NPs and Ag@Au coreshell NPs were loaded onto carbon-coated copper grids. The size and shape of the NPs were viewed using HR-TEM (FEI, TECNAI $\mathrm{T} 20 \mathrm{G}^{2}$ ), attached with EDX.

Fourier transform infrared (FTIR) measurements. Fourier transform infrared (FTIR) spectroscopy measurements were recorded on PerkinElmer Spectrum IR Version 10.6.1 equipped with attenuated total reflection (ATR). Ag-1, Au, Ag/Au alloy NPs and Ag@Au core-shell NPs were measured in the range of 400$4000 \mathrm{~cm}^{-1}$ at $25^{\circ} \mathrm{C}$.

MTT assay. The selected Hep-2 and NIH 3T3 cell lines were cultured in Dulbecco's Modified Eagle's Medium (DMEM), with supplements of $10 \%$ fetal bovine serum (GIBCO, USA) and $1 \%$ antibiotic-antimycotic solution. The cultured cells were kept at $37{ }^{\circ} \mathrm{C}$ with $5 \% \mathrm{CO}_{2}$ in a $\mathrm{CO}_{2}$ incubator. The cytotoxicity assessment was analyzed by the 3-(4,5-dimethylthiazol-2-yl)-2,5di-phenyl-tetrazolium bromide (MTT) assay. Briefly, the cultured cells $\left(1 \times 10^{5}\right.$ cells per ml) were seeded in 96-well plates and treated with different concentrations of (0.4-25 nM) Ag-1, $\mathrm{Au}, \mathrm{Ag} / \mathrm{Au}-1$ to 2 alloy NPs and Ag@Au-3 to 8 core-shell NPs for $24 \mathrm{~h}$. After treatment, $100 \mu \mathrm{L}$ of MTT $\left(5 \mathrm{mg} \mathrm{ml}^{-1}\right)$ was added to the wells and incubated at $37^{\circ} \mathrm{C}$ for $4 \mathrm{~h}$ in the dark, then the media was removed and the formazan crystals were dissolved by using $200 \mu \mathrm{L}$ of di-methyl sulfoxide (DMSO). The absorbance was measured at $570 \mathrm{~nm}$ using a microplate reader (THERMO Multiskan, USA). The percentage of cytotoxicity is calculated in both normal and Hep-2 cells, which is directly proportional to the control cells (untreated).

DAPI staining. Subsequently, the cultured Hep-2 cells in 6well plates were treated with their dose-dependent concentrations for $24 \mathrm{~h}$, and these cells were stained with DAPI to assess their nuclear integrity. After treatment for $24 \mathrm{~h}$, the media was expelled delicately, and the cells were rinsed twice with phosphate buffered saline (PBS), later it was fixed in $4 \%$ paraformaldehyde for $20 \mathrm{~min}$ in the dark. The fixed cells were again washed with PBS and stained with DAPI $\left(10 \mu \mathrm{g} \mathrm{ml}^{-1}\right)$ at $37^{\circ} \mathrm{C}$ for $20 \mathrm{~min}$ in the dark. The unbound excess stains were then washed with $10 \%$ methanol followed by PBS. The cells were visualized immediately under a fluorescence microscope (Nikon Eclipse, Inc., Japan) using the appropriate filter.

Rhodamine 123 staining. The Hep-2 cells were seeded in 6well plates $\left(1 \times 10^{5}\right.$ cells per well $)$ and left to stand for $60-80 \%$ confluence before being exposed to their dose-dependent concentrations of Ag/Au-1 to 2 alloy NPs and Ag@Au-3 to 8 coreshell NPs. After the specific time interval $(24 \mathrm{~h})$, the cells were fixed in $4 \%$ paraformaldehyde, washed twice with PBS, and exposed to the $\Delta \psi_{\mathrm{m}}$ specific stain Rhodamine 123 (Rh-123) $\left(10 \mu \mathrm{g} \mathrm{ml}^{-1}\right)$ for $30 \mathrm{~min}$ at $37{ }^{\circ} \mathrm{C}$. The stained cells were then rinsed twice with methanol and again using PBS. The stained cells were analyzed for their changes in $\Delta \psi_{\mathrm{m}}$ using a fluorescence microscope.

Analysis of cell cycle using propidium iodide staining. Flow cytometric analysis (FACS) was performed to evaluate the distribution of the cell cycle phases. The cells $\left(1 \times 10^{6}\right)$ were seeded and were each treated with Ag/Au-1 to 2 alloy NPs and Ag@Au-3 to 8 core-shell NPs for $48 \mathrm{~h}$. The cells were then collected by 
trypsinization and pelleted at $2500 \mathrm{rpm}$ for $5 \mathrm{~min}$ at room temperature. The cells were re-suspended in $300 \mu \mathrm{l}$ of PBS-EDTA to which $700 \mu \mathrm{l}$ of ice-cold $70 \%$ ethanol was added dropwise under stirring conditions. The arrangement was added delicately to guarantee a total blend of ethanol, and the samples were stored at $0{ }^{\circ} \mathrm{C}$ overnight. In this way, $1: 100$ volumes of $20 \mathrm{mg} \mathrm{ml}^{-1}$ RNase were included, and the mixture was incubated at $37{ }^{\circ} \mathrm{C}$ for $1 \mathrm{~h}$. Finally, propidium iodide was added to a final concentration of 50 $\mu \mathrm{g} \mathrm{ml} \mathrm{m}^{-1}$ and incubated for 10-20 $\mathrm{min}$ at room temperature. The stained cells were analyzed for DNA histograms and the distribution of the cell cycle phase was determined by flow cytometry.

\section{Results and discussion}

\subsection{UV visible spectroscopy}

The Ag/Au alloy NPs have a single surface plasmon resonance (SPR) band in the absorption spectrum and can be tuned with a different composition. Besides, monometallic $\mathrm{Au}$ and Ag-1 NPs were synthesized to compare their plasmonic properties. Fig. 1(A) shows the UV-visible spectra of monometallic Ag-1, Au NPs, and an alloy of Ag/Au-1 and Ag/Au-2 synthesized using the COCO gemini surfactant (16-6-16) as a capping agent. The SPR of monometallic $\mathrm{Ag}$ and Au NPs exhibited absorbance peaks at $405 \mathrm{~nm}$ and $532 \mathrm{~nm}$, respectively. It is clear from the spectra that the plasmon band is red-shifted significantly (as compared to the monometallic Ag-1 NPs band) with the incorporation of $\mathrm{Au}$ into $\mathrm{Ag}$ to synthesise an alloy of $\mathrm{Ag} / \mathrm{Au}-1$ and 2 . The SPR band shifted to 495 and $525 \mathrm{~nm}$ for $\mathrm{Ag} / \mathrm{Au}-1$ and $\mathrm{Ag} / \mathrm{Au}-2$, respectively, this intermediate band position indicates the formation of a bimetallic $\mathrm{Ag} / \mathrm{Au}$ NPs alloy nanostructure rather than a coreshell. However, only a slight shift was observed with a further increase in the Au precursor concentration (Fig. 1(B)), the band is detected in the case of Ag core Au shell Ag@Au-3 to Ag@Au-8 at $\lambda_{\max }=522,523,531,532,518$, and $523 \mathrm{~nm}$, respectively. Higher $\mathrm{Au}$ concentrations exhibit plasmonic peaks in the $\mathrm{Au}$ SPR absorption region and there has not been a shift in position as significantly as the first two concentrations (Ag/Au-1 and 2). The plasmon peak positions of the alloy NPs are associated with the weight proportions of $\mathrm{Ag} / \mathrm{Au} .^{49,50}$ The absence of two plasmonic bands (generally appearing in the physical mixture of monometallic $\mathrm{Au}$ and Ag NPs, which represents no alloy formation $)^{51,52}$ further confirms the formation of homogeneously mixed bimetallic alloys nanostructures without any significant formation of independent particles.

\subsection{X-ray diffraction (XRD) spectroscopy}

Fig. 1(C) shows the XRD patterns of $\mathrm{Ag}-1, \mathrm{Au}, \mathrm{Ag} / \mathrm{Au}$ alloy, and $\mathrm{Ag} @ A u$ core-shell NPs. The $2 \theta$ values of $\mathrm{Ag} / \mathrm{Au}-1$ to 2 alloys and $\mathrm{Ag} @ \mathrm{Au}-3$ to 4 core-shells are near one another since $\mathrm{Ag}$ and $\mathrm{Au}$ metals have the same lattice constants (JCPDS: 4-0783 and 40784). ${ }^{53}$ However, four intense peaks are seen at $2 \theta=38.2^{\circ}$, $45.3^{\circ}, 65.3^{\circ}$ and $77.8^{\circ}$ corresponding to (111), (200), (220) and (311), which are facets of the face-centered cubic (fcc) structures of Ag/Au-1 to 2 alloys and Ag@Au-3 to 4 core-shell NPs as shown in Fig. 1(C). On account of the Au@Ag-5 to 8 core-shell NPs, all of the diffraction patterns (see, Fig. S1 ESI $\dagger$ ) demonstrate only a weak and expansive diffraction peak ( $2 \theta$ about 37.8 ) corresponding to the (111) reflection. This suggests that the prepared particles have a tiny size and a face-centered cubic (fcc) structure. The outcomes likewise demonstrate that the (200) diffraction peak ( $2 \theta$ about 44.2 ) cannot be very much observed. The intensity ratio between the (111) and the (200) diffraction peaks of the Au@Ag-5 to 8 core-shell NPs was a lot higher than that (52 vs. 100) of JCPDS: 04-0784, indicating that our Au@Ag-58 core-shell NPs were abundant in (100) facets. ${ }^{54}$ The normal crystallite sizes of the particles are shown in Table 2. XRD gives the crystallite size, i.e., the normal width of the coherently scattering domains, which is not really equivalent to the domain size that is obvious in the TEM. ${ }^{48}$

\subsection{Fourier transform infrared (FTIR) spectroscopy}

The COCO gemini surfactant on the surface of the synthesized Ag-1, Au, Ag/Au alloy and Ag@Au core-shell NPs was examined by FTIR spectra. From the FTIR spectra, Ag-1, Au, Ag/Au alloy and $\mathrm{Ag} @ \mathrm{Au}$ core-shell NPs show the characteristic $\mathrm{CH}_{2}$ and $\mathrm{CH}_{3}$ vibration peaks for a long-chain hydrocarbon of surfactant and are depicted in Fig. 1(D), which are similar to the $\mathrm{CH}_{2}$ and $\mathrm{CH}_{3}$ vibration peaks for the free COCO gemini surfactant. It is noteworthy that the vibration of methylene segments (both symmetric and anti-symmetric) can be used as a sensitive indicator of the ordering of the alkyl chain and the higher energy of the $\mathrm{CH}_{2}$ vibration corresponds to the frequency of gauche defects in the hydrocarbon chain of surfactant. Both the vibration waves (symmetric and anti-symmetric) of the $\mathrm{CH}_{2}$ segments of the COCO gemini surfactant capped Ag/Au-1 to 2 alloy and Ag@Au-3 to 8 core-shell NPs are located at 2846 and $2921 \mathrm{~cm}^{-1}$, respectively and show a light shift to higher frequency in comparison with the $\mathrm{CH}_{2}$ vibrations of the pure COCO gemini surfactant which are present at 2853 and $2921 \mathrm{~cm}^{-1}$, respectively. The higher surface coverage of COCOGS on the $\mathrm{Ag} / \mathrm{Au}$ alloy and Ag@Au core-shell NPs is demonstrated by the shift of the methylene band to higher energy. The FTIR spectra of the COCOGS capped Ag/Au alloy and Ag@Au core-shell NPs show a peak at $1472 \mathrm{~cm}^{-1}$ for the stretching mode of $\mathrm{C}-\mathrm{N}^{+}$to the AuNPs surface. The presence of these peaks in the $\mathrm{Ag} / \mathrm{Au}$ alloy and Ag@Au core-shell NPs spectra indicate that the COCO gemini surfactant is adsorbed onto the NPs.

\subsection{High-resolution transmission electron microscopy (HRTEM)}

Fig. 2(A) and (B) are the HRTEM images of Ag-1 NPs and AuNPs, respectively, capped by the COCO gemini surfactant. The highresolution images (upper portion of each right-hand-side image) illustrate the synthesis of Ag-1 NPs and AuNPs. Most particles were nearly spherical and the size distribution histogram (Fig. 3(A) and (B)) shows an average size of $4.7 \mathrm{~nm}$ for the AgNPs and $11.6 \mathrm{~nm}$ for the AuNPs. The lattice fringes in the HRTEM image are $0.236 \mathrm{~nm}$ apart, which concurs well with the (111) lattice spacing of fcc Ag.

To determine the role of the COCO gemini surfactant in the shape development process, a precise report has been carried out. TEM and HRTEM were then used to analyse the alloy and 

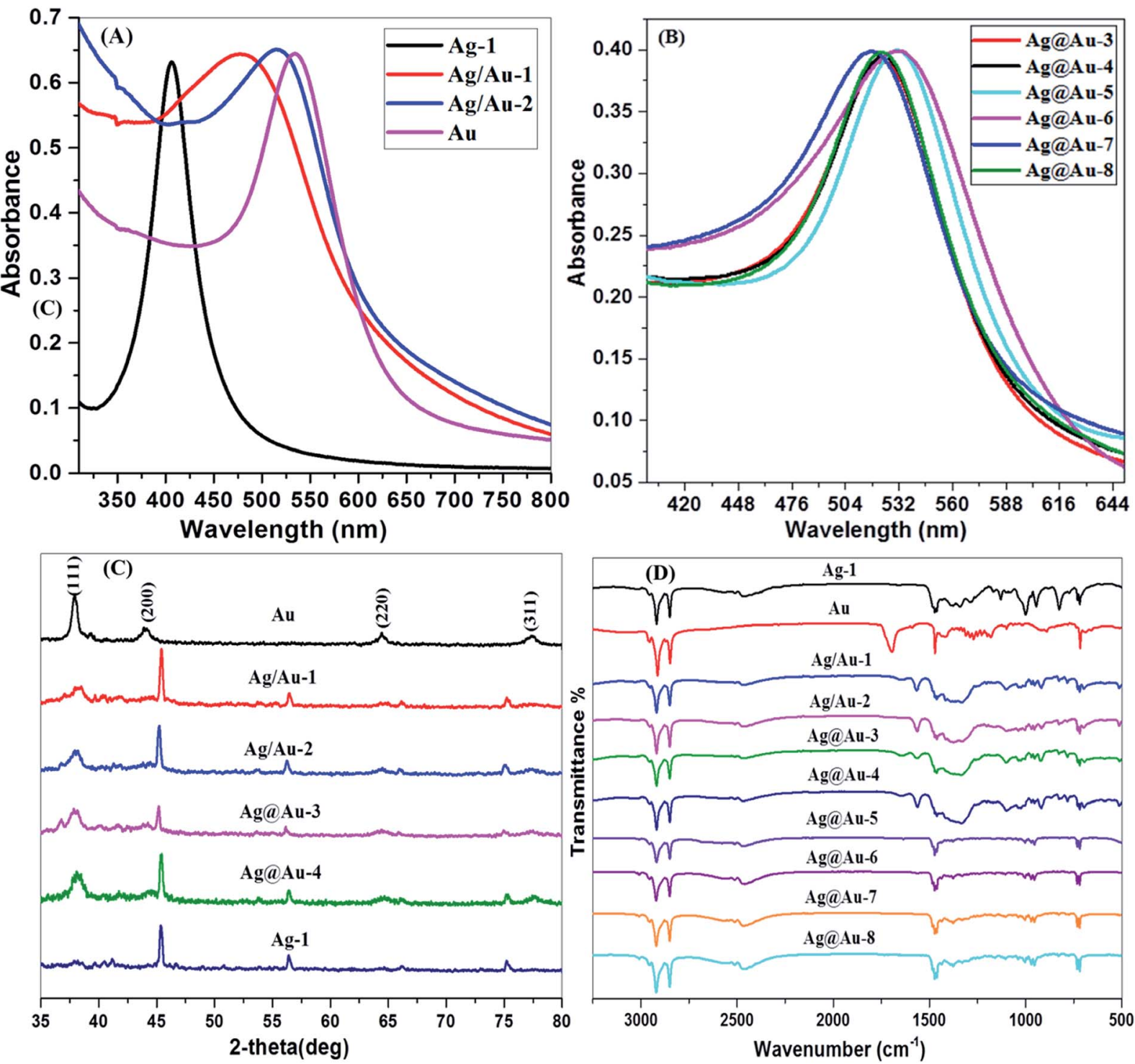

Fig. 1 UV-visible spectra of Ag-1, Au and Ag/Au alloy NPs (A), Ag@Au core-shell NPs (B), X-ray diffraction pattern illustrating the crystalline nature of the Ag-1, Au and Ag/Au alloy NPs (C) and FTIR spectra of Ag-1, Au and Ag/Au alloy NPs and Ag@Au core-shell NPs (D).

core-shell NPs. TEM images of the Ag@Au core-shell NPs are known to show banding in the electron density with a dark gold region and a silver light region. ${ }^{55}$ The TEM images of the alloy NPs prepared here in Fig. 2(C) and (D) did not show any electron density banding. If the particles were alloyed then there will be uniform complexity for every particle showing that scattering was circulated evenly all through the particle volume. HRTEM also confirmed the absence of electron density banding. Fig. 2(C) and (D) show the high resolution (upper portion of each right-hand-side image) image of the NPs in Ag/Au-1 and $\mathrm{Ag} / \mathrm{Au}-2$. Most of the particles were spherical, and the size distribution histogram (Fig. 3(C) and (D)) shows an average size of $4.7 \mathrm{~nm}$ for $\mathrm{Ag} / \mathrm{Au}-1$ and $5 \mathrm{~nm}$ for $\mathrm{Ag} / \mathrm{Au}-2$. The average diameters and standard deviations are given in Table 2 .

Fig. 4 shows that the Ag@Au-3 to 8 core-shell NPs have the same appearance except for the size of the particles; this can be tuned simply by altering the synthesis conditions (see Table S1
ESI $\dagger$ ). Also, among the different shapes of the Ag@Au core-shell NPs, triangular, hexagon, and rod shape can be seen. This demonstrates that the longer hydrocarbon chain length of (166-16) fundamentally influences the shape and development of NPs. ${ }^{56}$ Fig. 4(A)-(F) showing the high magnification images (upper portion of each right-hand-side image) clearly show that the Ag@Au core-shell NPs were spherical, triangular, hexagon and rod shaped and the size distribution histogram (Fig. 3(E) and (F) and S2(A)-(D) ESI $\dagger$ ) shows an average size of 14, 12.4, 13, 12.3, 7.1 and 7.6 nm for Ag@Au-3, Ag@Au-4, Ag@Au-5, Ag@Au6, Ag@Au-7 and Ag@Au-8, respectively. The average diameters and standard deviations are given in Table 2. Along these lines, it may be construed that the hydrocarbon chain length of the COCO gemini surfactant (16-6-16) significantly affects the development of the Ag@Au core-shell NPs. Dolly Rana et al. investigated the role of the hydrocarbon chain length and the twin tail surfactant (TTS) concentration significantly influenced 
Table 1 The concentration Ag-1, Au, Au/Ag alloy and Ag@Au core-shell NPs by ICP-OES and EDX. All given errors are standard deviations

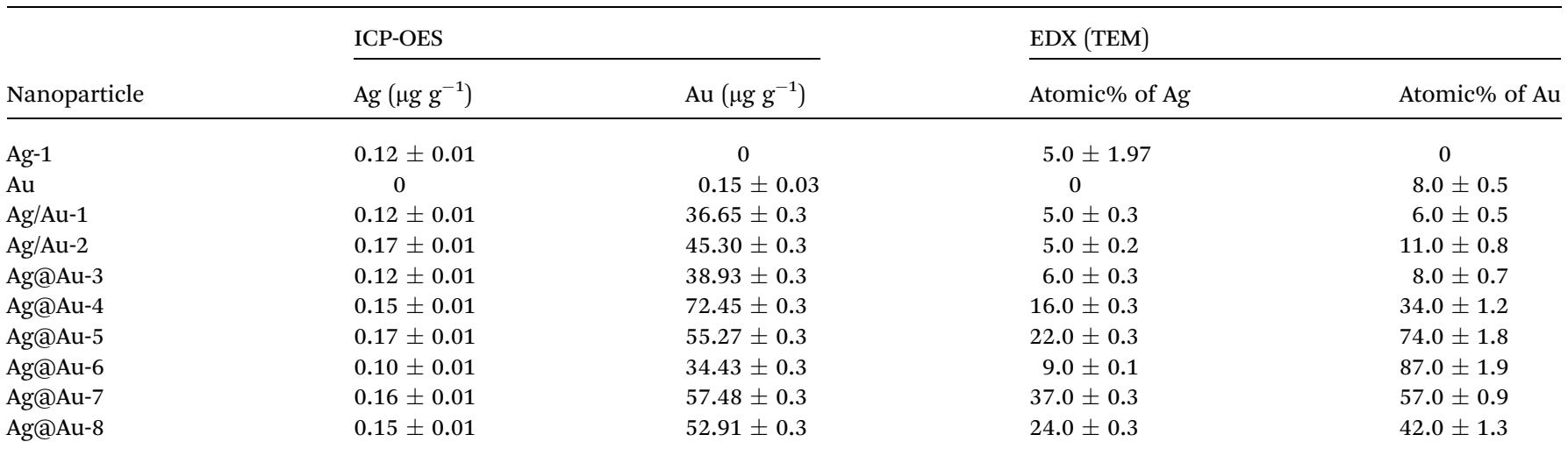

the shape and size of the Au NPs. TTS advances the development of Au NPs with a triangular shape. The outcomes propose that the TTS acts as a shape-coordinating operator for the development of Au NPs. Along these lines, streamlining of the chain length is basic for acquiring the desired shape of the NPs. ${ }^{56}$ The longer hydrocarbon chain of the COCO gemini surfactant promotes the growth of triangular, hexagon, and rodshaped NPs. J. C. Love and O. Magnussen discussed in previous reports about the change of shape from hexagonal to triangular. ${ }^{57,58}$ The gemini surfactant has more extended hydrocarbon chains spread over the surface, which provide strong interfacial adsorption and bring about the development of AuNPs. A beneficial surfactant adsorbed on the outside of AuNPs accordingly advances the development of NPs. This suggests that a long hydrocarbon chain promotes a quicker NP development in contrast with surfactants with shorter length hydrocarbon chains. ${ }^{56}$

The TEM image in Fig. 4 again clearly indicates two distinct complexes all through the NPs. The clear core-shell differentiation comprising darker external shells and lighter inward cores began from the $\mathrm{Ag}$ and $\mathrm{Au}$ components since Au scatters more electrons than Ag. ${ }^{59}$ Fig. 2(A) and (B) show the selected area electron diffractogram (SAED) obtained from the monometallic $\mathrm{Ag}-1, \mathrm{Au}$ and alloy of $\mathrm{Ag} / \mathrm{Au}$ NPs, which revealed the Debye-

Table 2 Nanoparticle diameter obtained by various methods and calculated crystallite sizes obtained from X-ray powder diffraction. All given errors are standard deviations

\begin{tabular}{lrll}
\hline & $\begin{array}{l}\text { TEM average } \\
\text { diameter }(\mathrm{nm})\end{array}$ & $\begin{array}{l}\text { Crystallite } \\
\text { size XRD }(\mathrm{nm})\end{array}$ & DLS Z-average (d nm) \\
\hline $\mathrm{Ag}-1$ & $4.7 \pm 0.1$ & $26.2 \pm 0.1$ & $27.3 \pm 6.9$ \\
$\mathrm{Au}$ & $11.6 \pm 0.3$ & $15.6 \pm 0.8$ & $40.6 \pm 10.1$ \\
$\mathrm{Ag} / \mathrm{Au}-1$ & $4.7 \pm 0.1$ & $36.0 \pm 0.4$ & $47.9 \pm 13.4$ \\
$\mathrm{Ag} / \mathrm{Au}-2$ & $5.0 \pm 0.1$ & $39.0 \pm 0.8$ & $74.1 \pm 12.5$ \\
$\mathrm{Ag@Au-3}$ & $14.0 \pm 0.2$ & $30.7 \pm 0.1$ & $52.3 \pm 19.6$ \\
$\mathrm{Ag@Au-4}$ & $12.4 \pm 0.1$ & $11.9 \pm 0.6$ & $41.5 \pm 18.8$ \\
$\mathrm{Ag@Au-5}$ & $13.0 \pm 0.3$ & $17.5 \pm 0.3$ & $30.6 \pm 11.2$ \\
$\mathrm{Ag@Au-6}$ & $12.3 \pm 0.2$ & $38.2 \pm 0.2$ & $23.6 \pm 10.3$ \\
$\mathrm{Ag} @ A u-7$ & $7.1 \pm 0.7$ & $10.4 \pm 0.1$ & $40.6 \pm 13.3$ \\
$\mathrm{Ag@Au-8}$ & $7.6 \pm 0.1$ & $12.6 \pm 0.1$ & $42.1 \pm 21.2$
\end{tabular}

Scherrer spots corresponding to a face-centered cubic (fcc) structure. For monometallic Ag-1 NPs, the SAED pattern consists of plane distances $2.35 \AA, 2.04 \AA$, $1.45 \AA, 1.25 \AA$ and 0.94 $\AA$, corresponding to the planes (111), (200), (220), (311) and (331) of the pure fcc silver structure (JCPDS, file no. 4-0787). Likewise, monometallic Au NPs consist of plane distances 2.30 $\AA, 2.03 \AA, 1.44 \AA, 1.23 \AA$ and $0.94 \AA$, corresponding to the planes (111), (200), (220), (311) and (331) of a pure fcc gold structure (JCPDS, file no. 4-0784). ${ }^{60}$ In the case of alloys, as the $\mathrm{Ag}$ and $\mathrm{Au}$ have very close crystal lattice parameters $(4.0862$ and $4.0783 \AA$ for $\mathrm{Ag}$ and $\mathrm{Au}$, respectively, lattice mismatch-0.17\%), ${ }^{5,61}$ it would be very difficult to observe any shifts in the diffraction ring positions. Hence, no clear interface of $\mathrm{Au}$ and $\mathrm{Ag}$ has been observed additionally, the Kirkendall effect in the $\mathrm{Ag} / \mathrm{Au}$ system could also contribute to this difficulty in distinguishing their diffraction rings. ${ }^{61}$ However, the SAED pattern of the Ag/Au alloy NPs is quite different in which a much closer set of diffraction spots along with $\mathrm{Ag}$ have been observed which correspond to (111), (220), (311) and (331) Bragg's reflections of Au (the much closer spots are circled in yellow color). This observation in $\mathrm{Ag} /$ $\mathrm{Au}$ alloy NPs indicates the co-existence of the crystal orientations of $\mathrm{Ag}$ and $\mathrm{Au}$ in a single particle. Noel has reported a similar kind of observation on an $\mathrm{Ag} / \mathrm{Au}$ nanocomposite. ${ }^{62}$

Similarly, Fig. 4(A) and (F) show the SAED patterns of this $\mathrm{Ag} @ A u-3$ to 8 core-shell NPs (lower portion of each right-handside image). The four ring patterns shown correspond to the $111,200,220$, and 311 reflections of the fcc structure similar to the alloy NPs. This demonstrates that the incident electron beam is perpendicular to the (001) faces of the fcc Au crystal shell along with the (001) directions of the fcc Ag crystal core through the Au@Ag-3 to 8. EDX analysis has been carried out to find the elemental composition of the NPs. Fig. S6(A) and (F) ESI $\uparrow$ show the presence of pure and Ag-1 and Au NPs, (C) and (D) show the EDX spectrum of Ag/Au-1 to 2 alloy NPs, and (E-H) show Ag@Au4, 3, 7, and 8 core-shell NPs, respectively. Table 1 shows the compositions of Ag/Au- 1 to 2 and Ag@Au-3 to 8 core-shell NPs. Additionally consistencies in the particle-to-particle structure, and the nearness of both $\mathrm{Ag}$ and Au in every particle affirmed that the particles were an Ag/Au alloy and Ag@Au core-shell NPs not a physical mixture of monometallic $\mathrm{Ag}$ and Au NPs. 

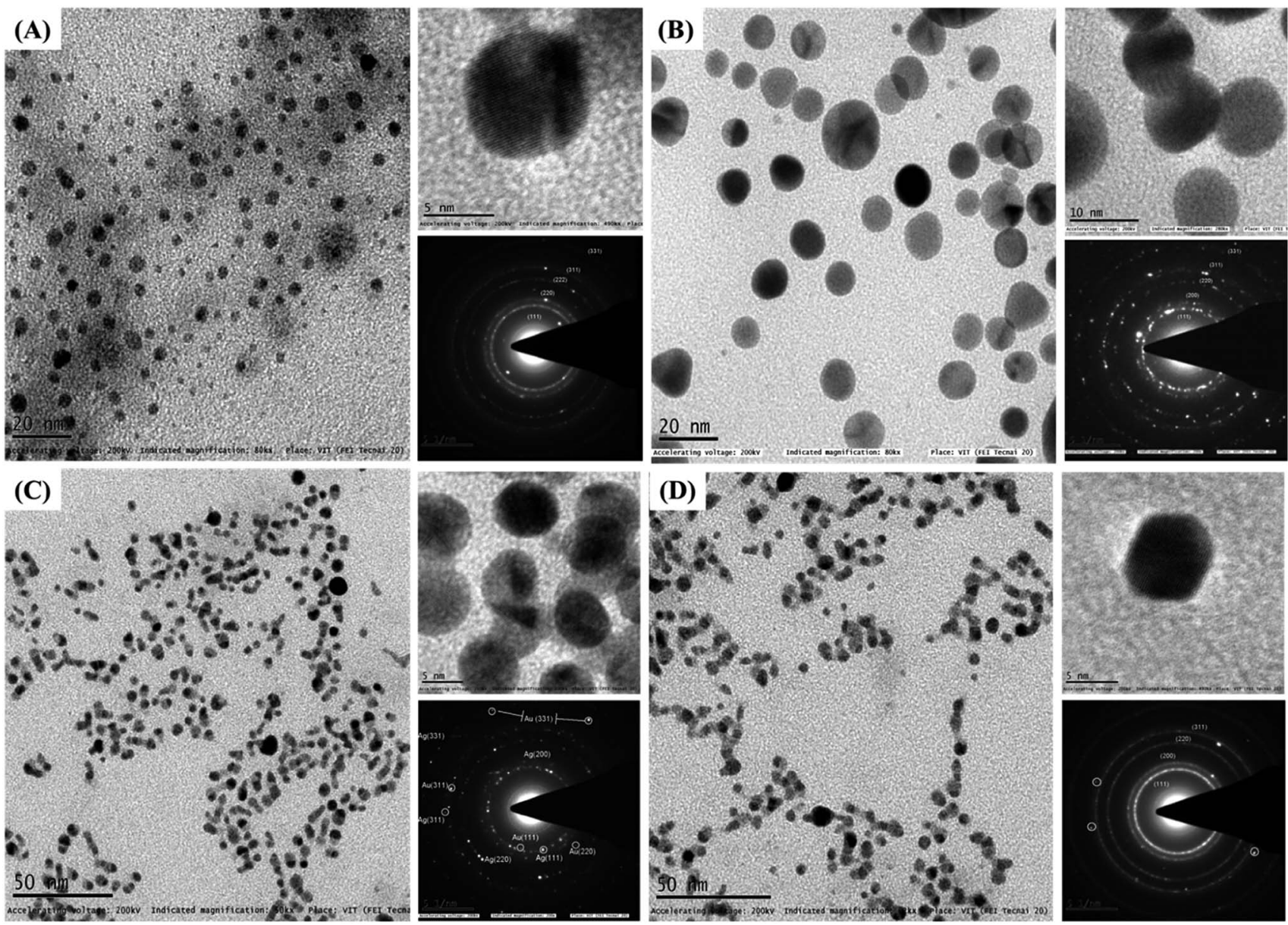

Fig. 2 TEM images of Ag-1 NPs (A), AuNPs (B) and Ag/Au-1 and Ag/Au-2 alloy NPs (C) and (D), respectively. The upper portion of each righthand-side image shows single nanoparticles at high magnification, whereas the SAED ring pattern in the lower part shows the crystal structure of the nanoparticles.

\subsection{Inductively coupled plasma-optical emission spectrometry (ICP-OES)}

The concentration of $\mathrm{Ag}-1, \mathrm{Au}, \mathrm{Ag} / \mathrm{Au}-1$ to 2 alloy and $\mathrm{Ag} @ \mathrm{Au}-3$ to 8 core-shell NPs was quantitatively estimated by ICP-OES analysis. These results are shown in Table 1.

\subsection{Dynamic light scattering (DLS) technique}

The dynamic light scattering (DLS) method was utilized to determine the hydrodynamic radii or size of the NPs. We see that the acquired DLS and TEM vary significantly for little NPs. While TEM gives the width of individual NPs, DLS likewise considers the ligand shell. Therefore it gives data on the size of the entire conjugate. In suspensions of little NPs, the quantity of surfactant atoms per molecule is high. Subsequently the hydrodynamic size obtained from DLS is more noteworthy than the size determined by TEM.

Fig. S3(A)-(F) ESI $\uparrow$ show that the hydrodynamic diameter values are 27.3, 40.5, 98.3, 62.3, 90.3 and $40.6 \mathrm{~nm}$ for $\mathrm{Ag}-1, \mathrm{Ag}-2$, $\mathrm{Ag}-3$, Ag-4, and Ag-5 NPs, respectively. The hydrodynamic diameter values are presented in Table S1 ESI. $\dagger$ Fig. S4(A)-(H) $\mathrm{ESI} \dagger$ show the hydrodynamic diameter values are 40.6, 47.9,
74.1, 52.3, 41.5, 30.6, 23.6, 40.6 and $42.1 \mathrm{~nm}$ for $\mathrm{Au}, \mathrm{Ag} / \mathrm{Au}-1, \mathrm{Ag} /$ Au-2, Au@Ag-3, Au@Ag-4, Au@Ag-5, Au@Ag-6, Au@Ag-7, and Au@Ag-8 alloy and core-shell NPs, respectively. The hydrodynamic diameter values are presented in Table 2.

Zeta potential measurements also studied the surface charge of these Ag/Au alloy and Au@Ag core-shell NPs. The stability of the NPs is more important when these items are utilized in biomedical applications. ${ }^{63}$ The zeta potential gives information about the NPs' surface charge and stability. NPs with zeta possibilities higher than $20.0 \mathrm{mV}$ or less than $-20.0 \mathrm{mV}$ have strong electrostatic repulsion and this makes the solution stable. ${ }^{64}$ The $\zeta$-potential values and PDI values of $\mathrm{Ag}$-1, $\mathrm{Au}, \mathrm{Ag} / \mathrm{Au}$ alloy, and Au@Ag core-shell NPs capped by COCOGS are shown in Table S2 ESI. $\uparrow$ The positive zeta potential values for $\mathrm{Ag} / \mathrm{Au}$ alloy and Au@Ag core-shell NPs suggest that the NP surfaces are covered by surfactant molecules and are highly stable. ${ }^{65}$ The high stability of Ag/Au alloy and Au@Ag core-shell NPs is significant for biomedical uses. The obtained Ag/Au alloy and Au@Ag coreshell NPs capped by the COCO gemini surfactant were stable in water medium for a long time, see Fig. S5(A)-(H) ESI. $\uparrow$ The used COCO gemini surfactant was very important for the formation and stabilization of the Ag/Au alloy and Au@Ag core-shell NPs. 

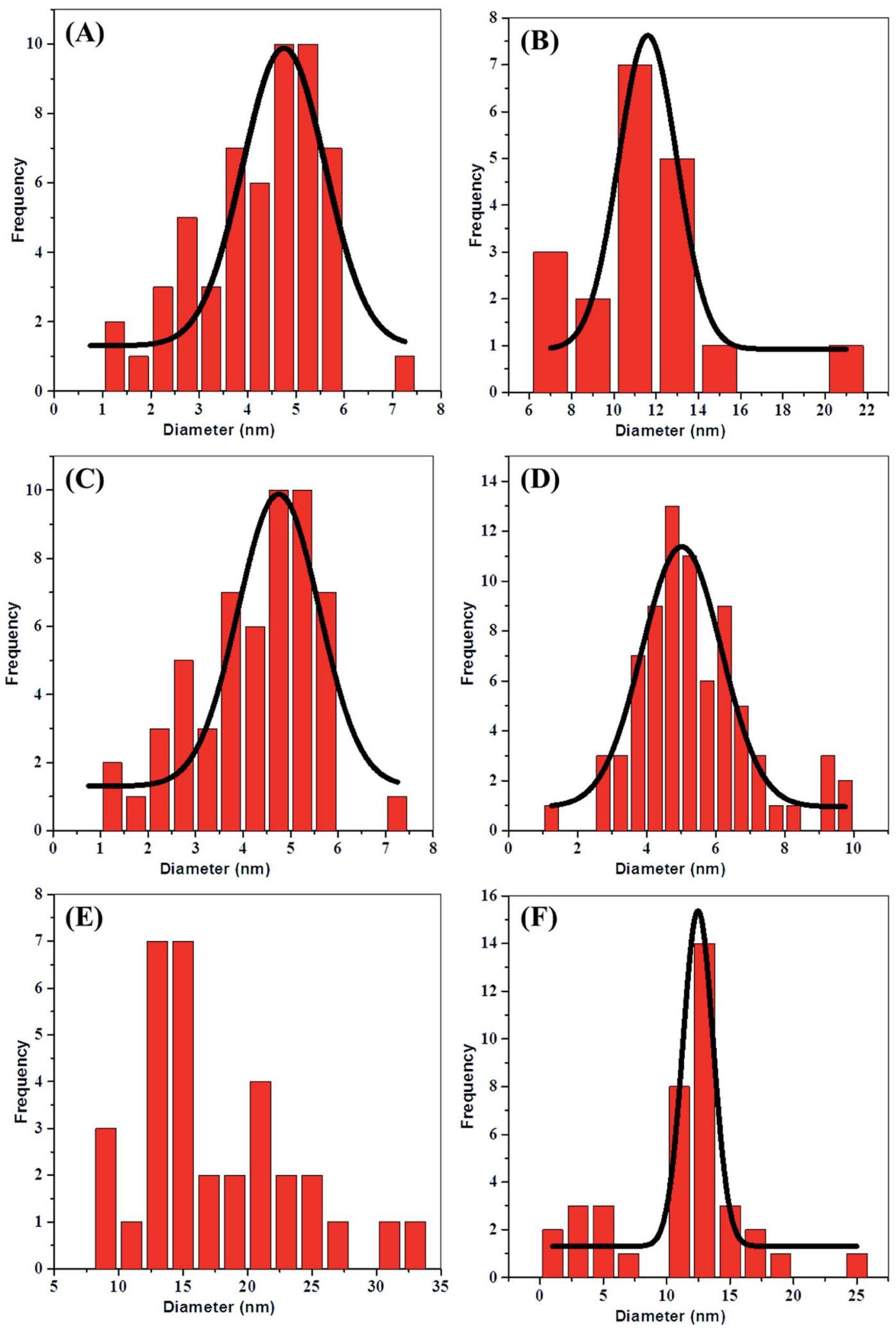

Fig. 3 Histogram showing the particle size distribution pattern for the corresponding TEM images (A) Ag-1 NPs, (B) AuNPs, (C and D) Ag/Au-1 and $\mathrm{Ag} / \mathrm{Au}-2$ alloy NPs and (E and F) Ag@Au-3 and Ag@Au-4 core-shell NPs.

The COCO gemini surfactant provides extra electrostatic stabilization and passivates the surface of the AuNPs formed. The molecules of the COCO gemini surfactant framed on the outside of the AuNPs in aqueous solution have a bilayer structure and they show great stability to $\mathrm{Ag} / \mathrm{Au}$ alloy and $\mathrm{Au} @ \mathrm{Ag}$ core-shell NPs due to their structure and high charge density. 

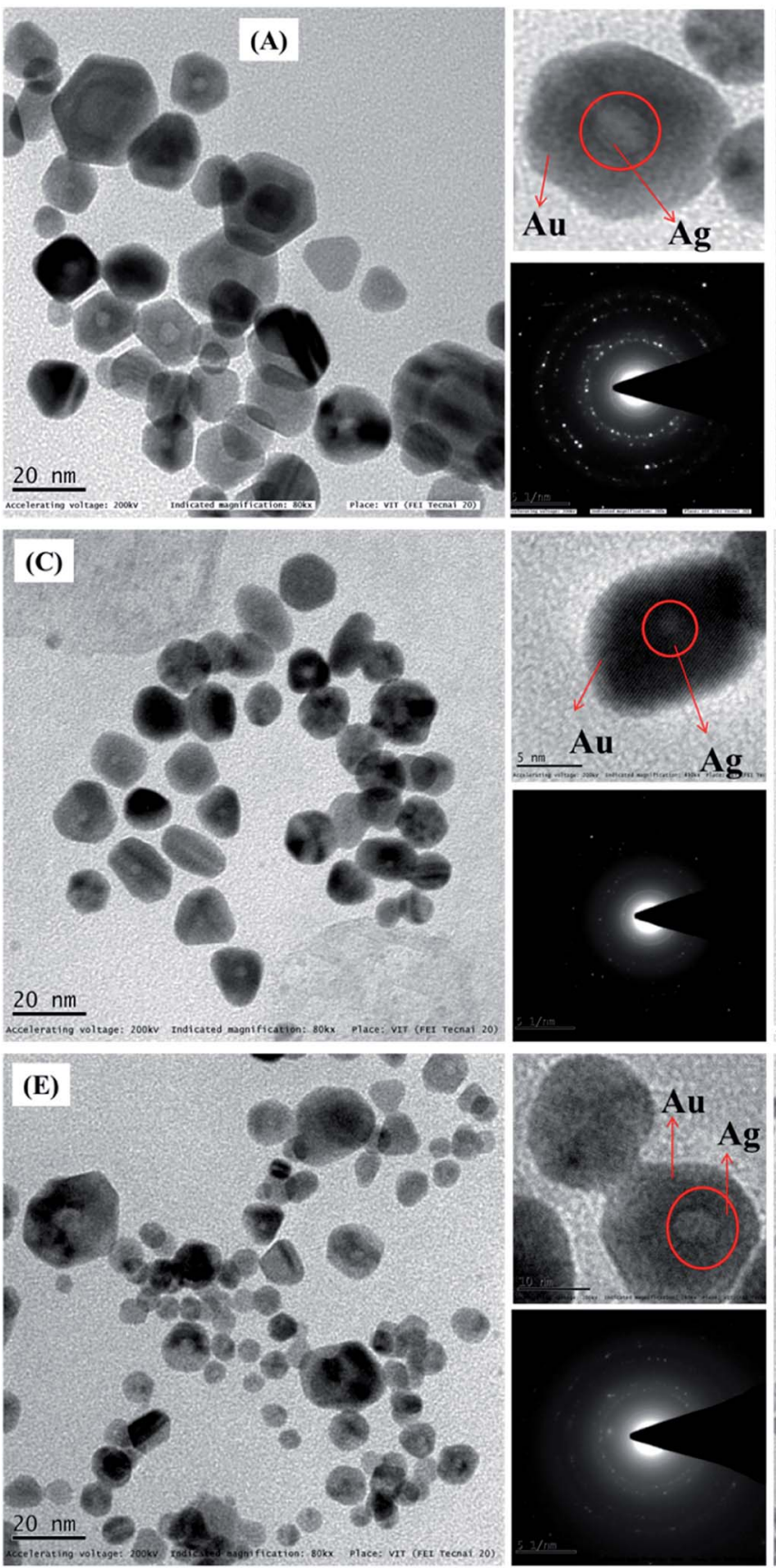
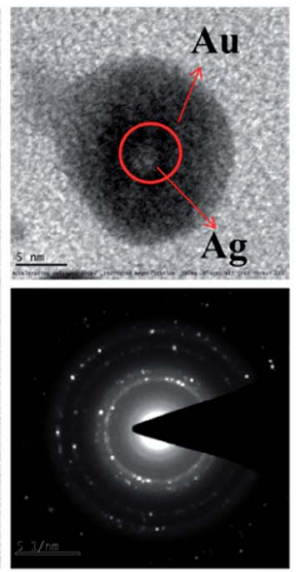

$50 \mathrm{~nm}+800$
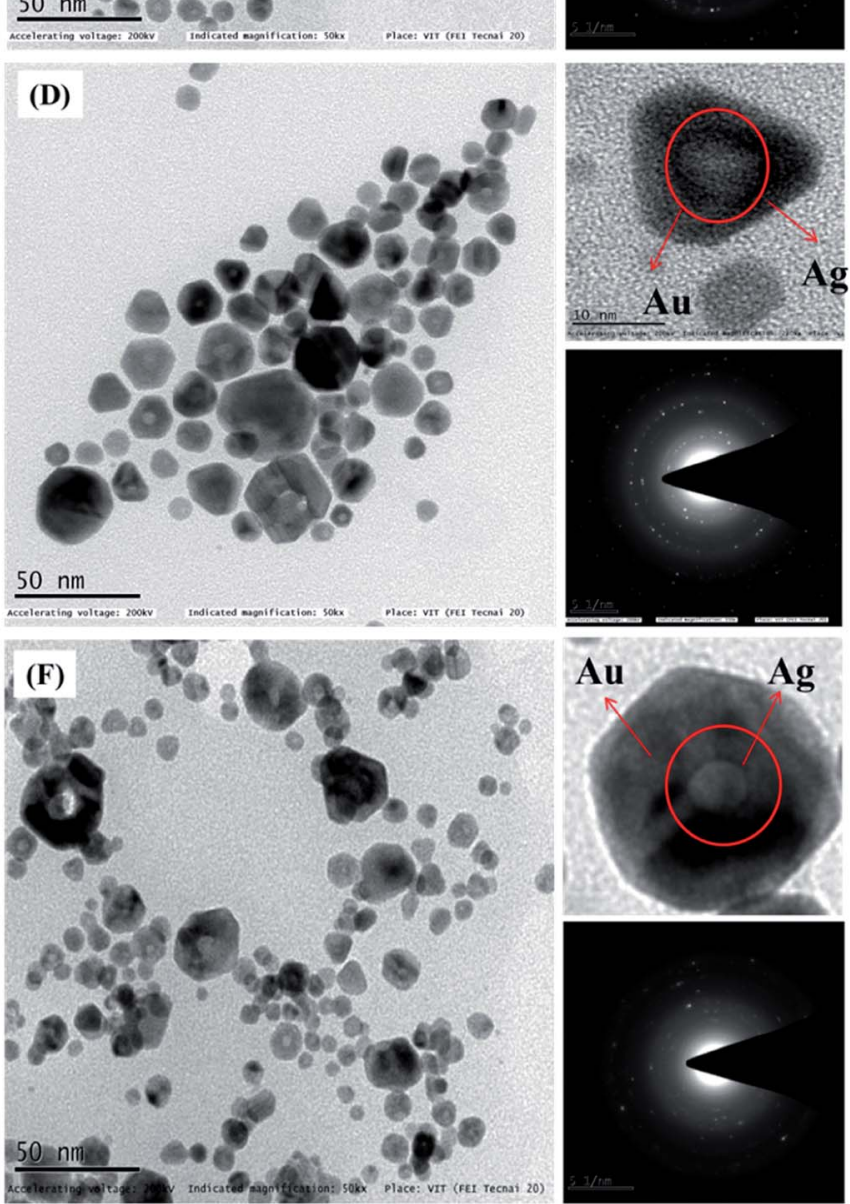
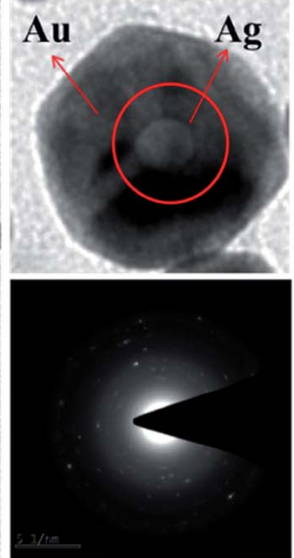

Fig. 4 TEM images of Ag@Au-3 to $8(A-F)$, respectively. The upper portion of each right-hand-side image shows single NPs at a high magnification, whereas the SAED ring pattern in the lower part shows the crystal structure of the NPs.

\subsection{Capping effect of COCO gemini surfactant (COCOGS, 16-} 6-16)

Scheme 1 represents the probable mechanism and shows the capping effect of the COCO gemini surfactant (16-6-16) AgNPs for the formation of Ag@Au core-shell NPs (A) and the formation of $\mathrm{Ag} / \mathrm{Au}$ alloy NPs (B). This sort of mechanism is clarified by aggregation growth. ${ }^{66}$ The capping agent is playing an important role here to stabilize the system. The capping agent plays a vital role for the 'aggregation growth' of the NP aggregates because of some kind of driving force connected to it. According to the capping mechanism, the conventional (monomeric) surfactant CTAB monomer adsorbs at the outside surface of NPs through electrostatic interactions. ${ }^{\mathbf{8 , 6 7 , 6 8}}$ In a similar way, COCO gemini surfactants follow the same mechanism. This occurs because of the electrostatic interactions of counter-ions $\left(\mathrm{Br}^{-}\right)$at the outside of the surface of NPs that consequently connects with the electropositive cationic head groups of the surfactant. However, since the COCO gemini surfactant has twin tails which cause more hydrophobicity than their homologous monomeric surfactants, ${ }^{69}$ therefore, the stronger hydrophobicity acts as a driving force for the aggregation of NPs in small aggregates. When the NPs are close 

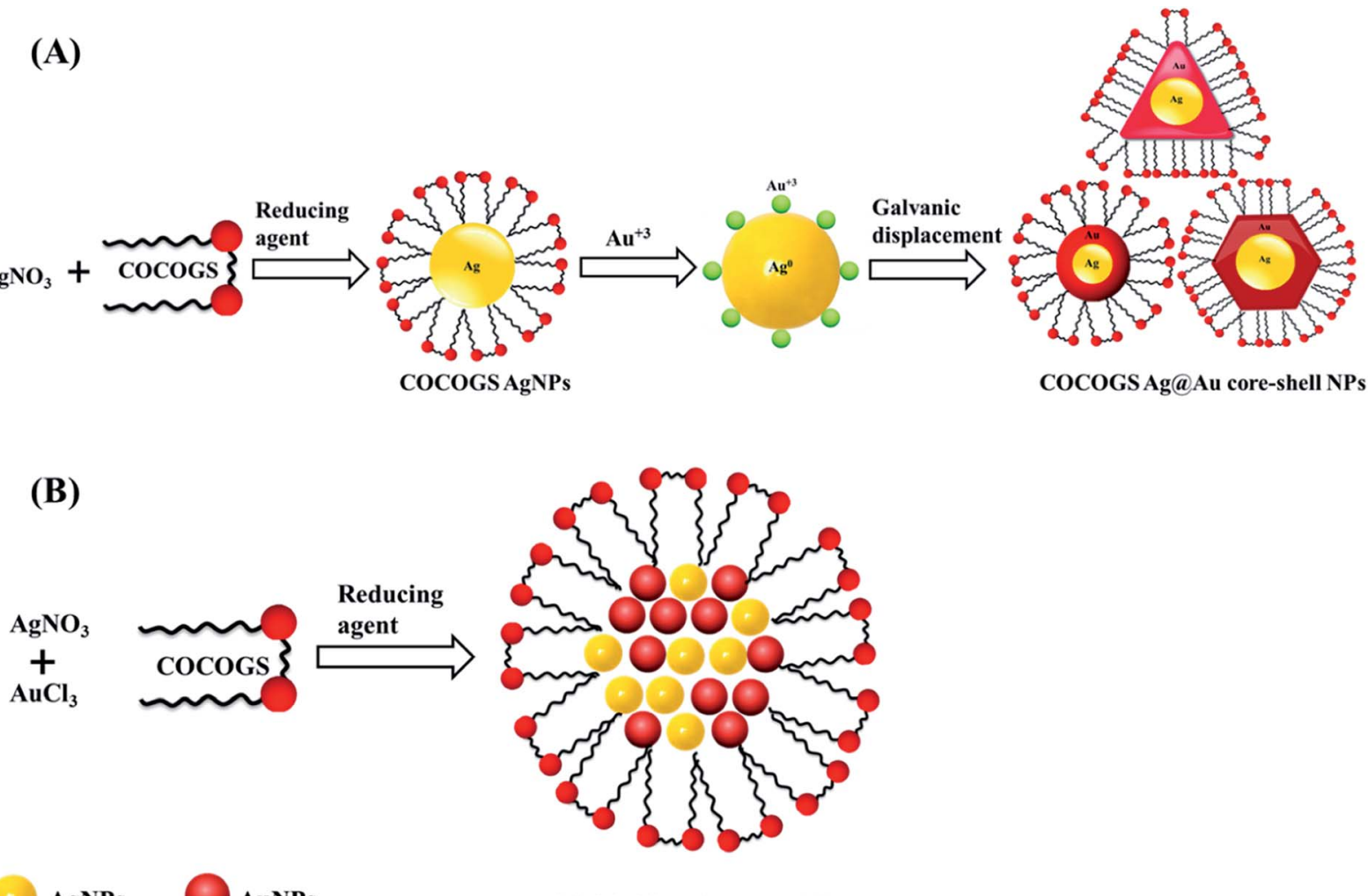

AgNPs

AuNPs

COCOGS Ag/Au alloy NPs

Scheme 1 Schematic representation showing the capping effect of the COCO gemini surfactant (16-6-16) AgNPs for the formation of Ag@Au core-shell NPs (A) and the formation of Ag/Au alloy NPs (B).

enough to each other, the further reduction of a metal ion into the metal atom activates the nucleation on the surface of the available NPs. ${ }^{70}$ This happens especially when the crystal plane of the anisotropic geometry is partially occupied by the surfactant monomers. For the most part, (111) planes are progressively inclined to promote nucleation in comparison. This can be attributed to the difference in reaction rates between the $\mathrm{Au}^{3+}$ ions and the surfactant passivizing the AgNPs surface and henceforth changing the galvanic Au deposition rate. The strong electrostatic interaction between the COCO gemini surfactant-AgNPs and the approaching $\mathrm{Au}^{3+}$ ions promotes faster $\mathrm{Au}$ deposition along with displacing the $\mathrm{Ag}$ atoms from its core, which is brought about in the formation of alloy and coreshell NPs as shown in Scheme 1.

\subsection{Analysis of cytotoxicity using Ag-1, Au, Au/Ag alloy and Ag@Au core-shell NPs}

The in vitro cytotoxicity of the synthesized AgNPs, AuNPs, Au/Ag1-2 alloy, and Ag@Au-3-8 core-shell NPs was investigated to determine anticancer potentials against the Hep-2 cancer cell lines and non-cancerous NIH3T3 cells lines by the MTT assay method assay and their cell growth inhibitory (antiproliferation) results are depicted in Fig. 5. Different concentrations of Ag-1, Au, Au/Ag-1-2 alloy, and Ag@Au-3-8 core-shell NPs ranging from 5 to $125 \mu \mathrm{g} \mathrm{ml} l^{-1}$ were applied to the cell lines and incubated for $24 \mathrm{~h}$.
There are many reports in the literature available on CTAB and CTAC capped NPs ${ }^{71-74}$ regarding cytotoxicity and their effect on cell growth. In this present study we aimed to focus only on gemini surfactant capped NPs and their cytotoxicity. Fig. 5(A) illustrates that $\mathrm{Ag}-1$ and $\mathrm{Au}$ NPs does not alter the viability of NIH3T3 even at a very high concentration of $5 \mu \mathrm{g} \mathrm{m}{ }^{-1}$, the sustainability of $90 \%$ healthy cells indicating that AuNPs and AgNPs are not toxic to the non-cancerous cells. On the other hand, the percentage viability of Hep-2 cells has been found to decrease in viability with dose dependent concentration. When the cells were treated with $15 \mu \mathrm{g} \mathrm{ml}{ }^{-1}$ of AuNPs and AgNPs, sustainability is $75 \% 50-100 \mu \mathrm{g} \mathrm{ml}^{-1}$ of AuNPs and AgNPs, which reduces the viability to a maximum of $50 \%$ to $25 \%$, respectively, and a lower value of $20 \%$ viability is observed at $125 \mu \mathrm{g} \mathrm{m} \mathrm{m}^{-1}$ treatment as shown in Fig. 5(B). In the case of single AuNPs and AgNPs, $\mathrm{IC}_{50}$ values of $125 \mu \mathrm{g} \mathrm{ml}{ }^{-1}$ for both AuNPs and AgNPs were observed against the NIH3T3 normal cell line, respectively, whereas $\mathrm{IC}_{50}$ values found against the Hep-2 cells are 75 and 50

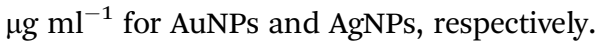

Fig. 5(C and D) illustrates that the $\mathrm{Au} / \mathrm{Ag}-1$ to 2 alloy and Ag@Au-3 to 8 core-shell NPs displayed a lower activity against the NIH3T3 cells as compared with the corresponding Hep-2 cells. The concentration of the test aggravate that acquires half decrease in cell viability or the half maximal inhibitory concentrations $\left(\mathrm{IC}_{50}\right)$ of compounds $(\mathrm{Au} / \mathrm{Ag}-1$ to 2 alloy and Ag@Au-3 to 8 core-shell NPs against the cancer cell lines), which are given in the Table S3 ESI. $\dagger$ The MTT assay results of 
(A)

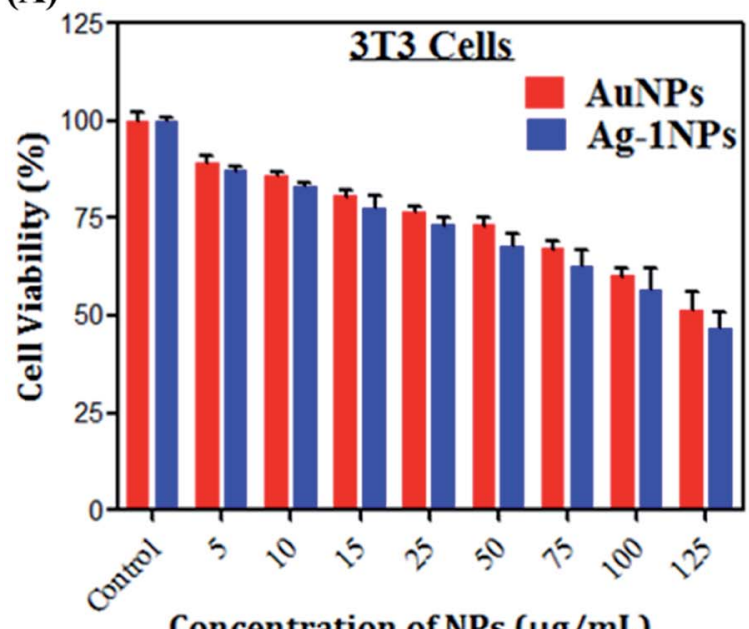

Concentration of NPs $(\mu \mathrm{g} / \mathrm{mL})$

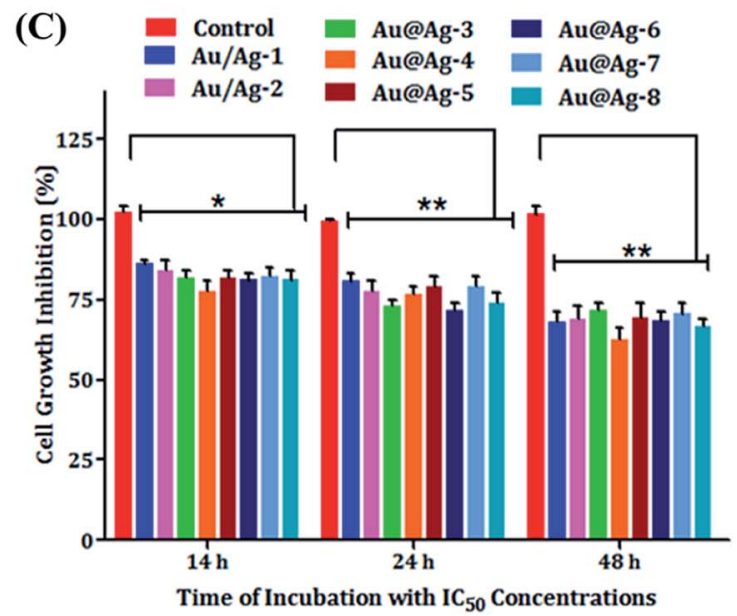

(B)

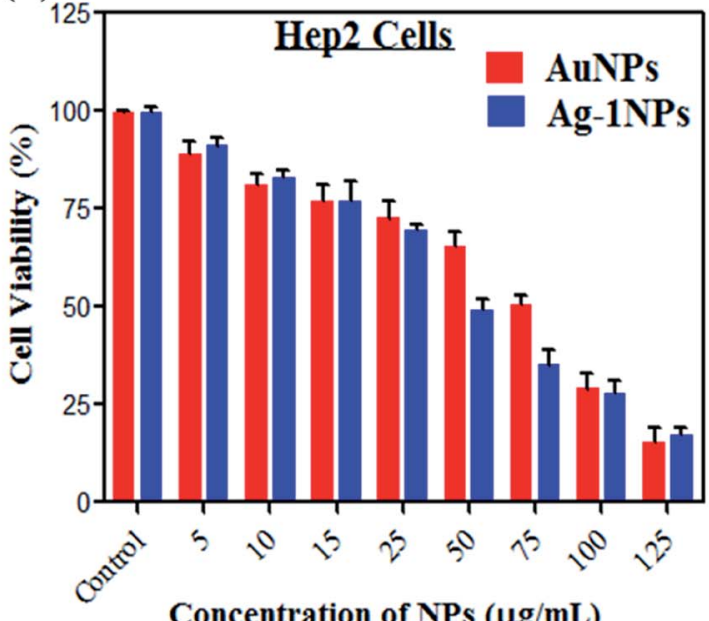

Concentration of NPs $(\mu \mathrm{g} / \mathrm{mL})$

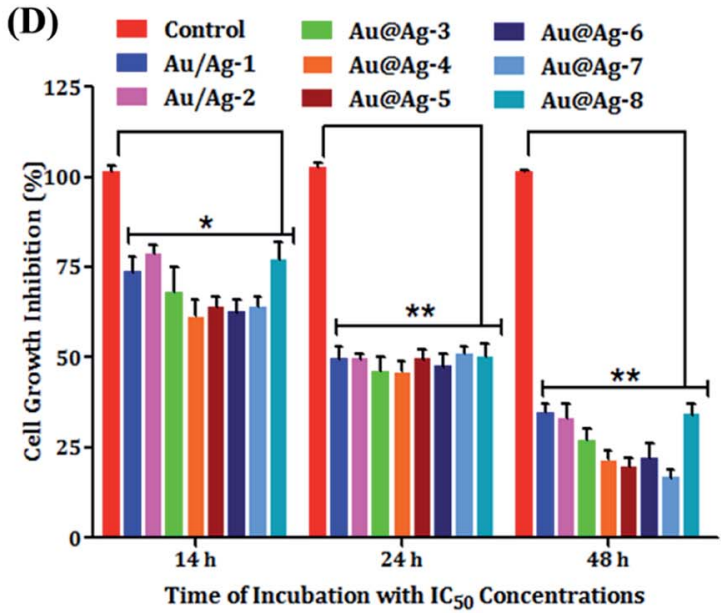

Fig. 5 Cytotoxicity assay is to measure cell proliferation using MTT. The anti-proliferative effect of AuNPs, Ag-1NPs, Au/Ag alloy and Ag@Au core-shell on (A) AuNPs and Ag-1 NPs against NIH3T3 cells, (B) AuNPs and AgNPs on Hep-2 cells, (C) Au/Ag alloy and Ag@Au core-shell against $\mathrm{NIH} 3 \mathrm{T3}$ cells and (D) Au/Ag alloy and Ag@Au core-shell on Hep-2 cells. There are two parallel experiments in a set of samples ( $N=2$ ).

Au/Ag-1-2 alloy and Ag@Au-3-8 core-shell NPs versus the Hep-2 cell lines are depicted in Fig. 5. In comparison with the control, the $\mathrm{Au} / \mathrm{Ag}-1-2$ alloy displayed an $\mathrm{IC}_{50}$ value against the Hep-2 cells. Nevertheless, Ag@Au-3, 6, and 8 core-shell NPs indicated higher anticancer potentials than the standard, yielding $\mathrm{IC}_{50}$ values of 10,5 , and $5 \mu \mathrm{g} \mathrm{ml}{ }^{-1}$ against Hep-2 cells, respectively. Ag@Au-4, 5 and 7 were found to be tolerably effectual against the Hep-2 cell line with the $\mathrm{IC}_{50}$ values of 25,35 and 20 $\mu \mathrm{g} \mathrm{ml}^{-1}$ respectively.

The capping agent seems to be by all accounts a basic factor for the assurance of the biological activity of nanoparticles by changing their surface properties, for example, charge, hydrophobicity, and functionality. While some authors have considered AuNPs to be non-toxic in spite of effective endocytic takeup into human cells, ${ }^{75,76}$ different outcomes have been obtained with respect to the cytotoxicity of AuNPs dependent on their size, shape, and surface chemistry. Accordingly, we have introduced a new class of dimeric counterion coupled gemini surfactant (COCOGS) to synthesise Au/Ag alloy and Ag@Au core-shell NPs, which led to enhanced stability and biocompatibility. The COCO gemini surfactant is considered a good stabilizer. The stabilization is generally explained regarding the charge (due to DLVO theory) ${ }^{77}$ and steric stabilization. Steric stabilization assumes a significant role when the AuNPs are covered by long tail surfactant molecules which provide a protective layer around the AuNPs. ${ }^{78}$ Such protective coatings from the adjoining NPs when intermingling with each other induce configurational constraints and keep the NPs separate from each other. This prevents coagulation and enhances further nucleation. Therefore, in conclusion, both electrostatic and steric stabilizations are required to keep the NPs stable in solution. Both properties are easily contributed by the ionic surfactants to stabilize NPs in solution. In the case of the present $\mathrm{COCO}$ gemini surfactant, apart from charge and steric stabilizations, the third most significant factor, i.e., the strong hydrophobic interactions, is mainly responsible for bringing about several COCO gemini surfactant capped NPs with distinct morphologies. Here, the NPs have already been prevented from coagulation by screening their short-range electrostatic interactions due to the presence of intervening 

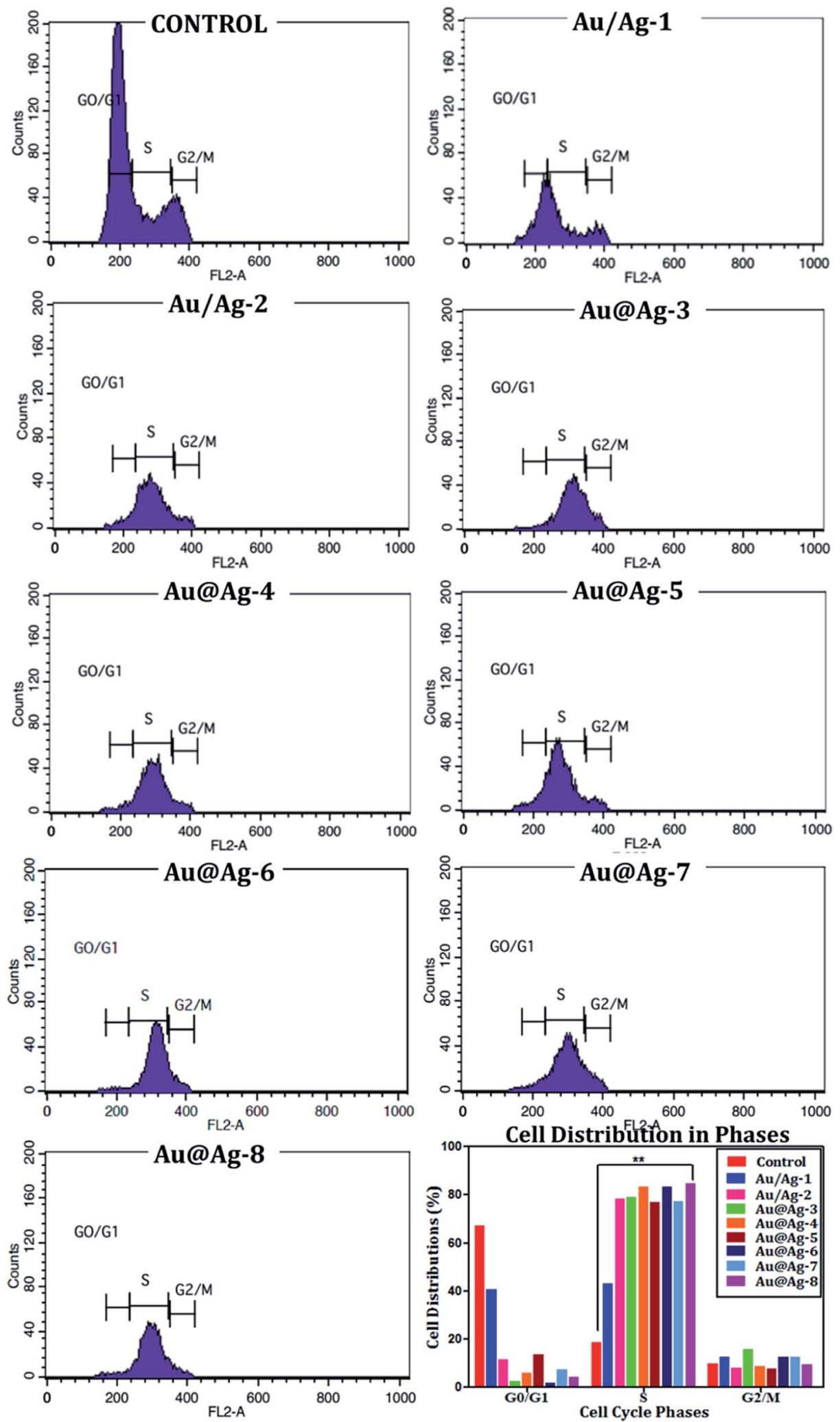

Fig. 6 Flow cytometry analysis of Hep-2 cells on treatment with different Au/Ag alloys and Ag@Au core-shells to assess the different phases of cell distribution.

hydrophobic domains. This concludes that a micellar arrangement of cationic double tail surfactants does indeed confer better stability than that obtained with a monomeric surfactant.
The use of COCO gemini surfactant in the present investigation prompted the advancement of high-quality alloy and core-shell NPs that display high anticancer activity on Hep-2 cancer cells. 


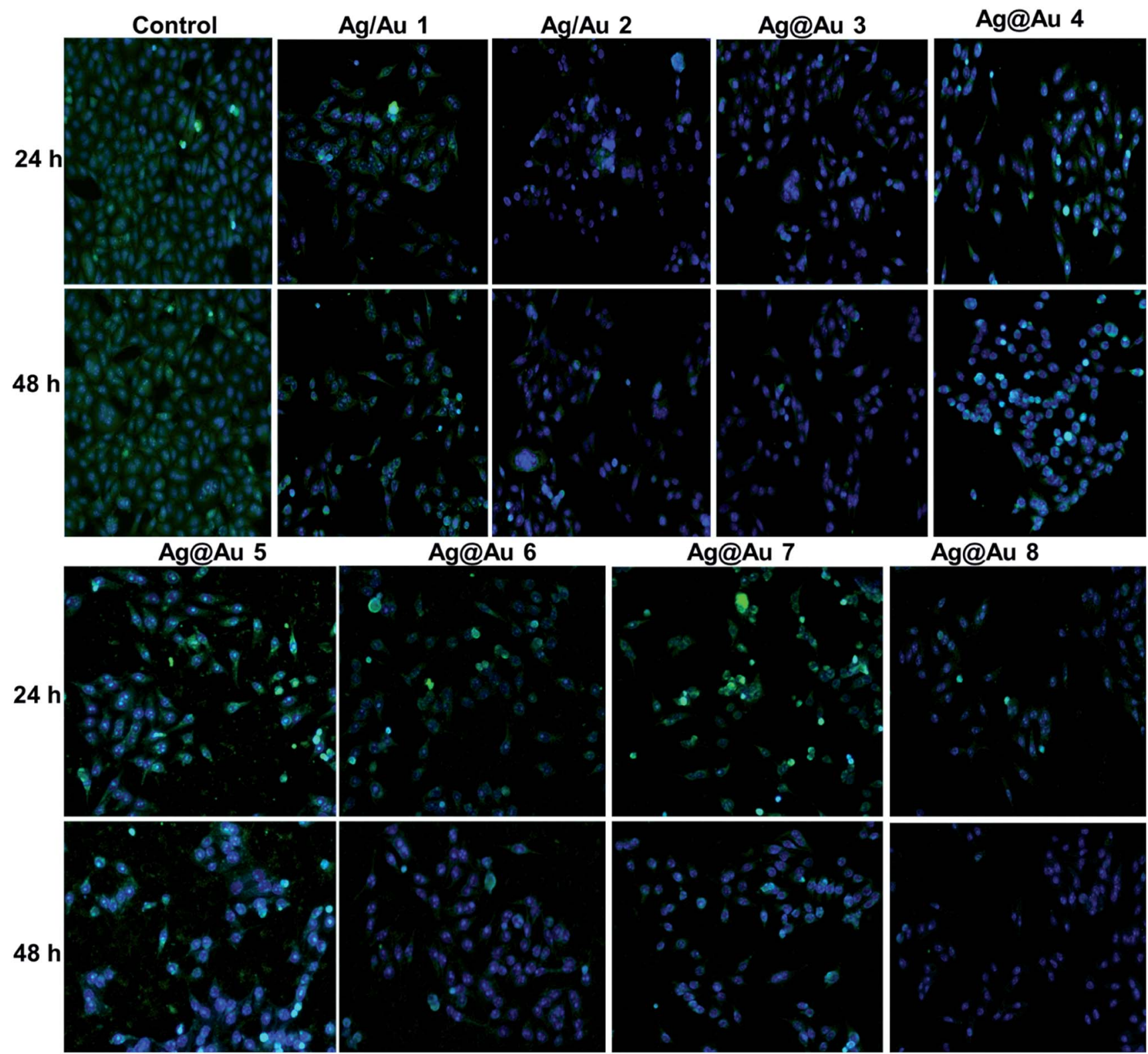

Fig. 7 Fluorescence microscopy images of Au/Ag alloy and Ag@Au core-shell treatment on Hep-2 cells at $24 \mathrm{~h}$ and $48 \mathrm{~h}$. The panel of images shows Rh-123 and DAPI staining for induction of mitochondrial depolarization and nuclear apoptosis; DAPI (blue) staining shows the nuclear fragmentation; Rh-123 (green) staining indicates the loss of mitochondrial membrane potential $\left(\Delta \psi_{\mathrm{m}}\right)$. Rh-123 indicates the active mitochondrial membranes with a green color and damaged nuclear materials are shown by DAPI (blue color).

\subsection{Influence of $\mathrm{Au} / \mathrm{Ag}$ alloy and $\mathrm{Ag@Au}$ core-shell NPs on} cell cycle arrest

A wide variety of signal biomarkers can trigger apoptosis. The morphological characteristics of the apoptosis are mainly due to the activation of effector caspases; their activation leads to the cleavage of genomic materials and some cell cycle regulators. ${ }^{79,80}$ The cell cycle is the conserved mechanism by which eukaryotic cells replicate themselves. In this study, the cell cycle distribution (DNA content) was quantified using PI staining by flow cytometric analysis, and the results are presented in Fig. 6. After treating Au/Ag-1 to 2 alloy and Ag@Au-3 to 8 core-shell NPs for $24 \mathrm{~h}$, a decrease in cell number in the G1-phase was observed and all the cell populations remain in the $S$ phase of the cell cycle. In response to a growth-promoting signal, cells enter into the $\mathrm{S}$ phase to duplicate DNA. However, due to DNA-damage or replicative stress, cells are arrested in the S-phase, which is different from not coming into the next phase of the cell cycle. An arrest in the S-phase implies that the cell is unable to duplicate its DNA, as a result of a decrease in the G2/M-phase as well as in the G0/G1 phase. ${ }^{81}$ They are unable to proceed to the next step of the cell cycle and continue to exhibit only at the $\mathrm{S}$ phase and show no evidence of re-establishing G0/G1markers or cyclin-dependent kinase inhibitors. ${ }^{82}$ Results from the present investigation revealed that the treatment of cancer cells with $\mathrm{Au} / \mathrm{Ag}$ alloy and Ag@Au core-shell NPs arrested primary cells at the S phase of the cell cycle in a concentration-dependent manner. Thus, this 
concludes that cells maintain a prolonged $\mathrm{S}$ phase arrest while remaining metabolically in the $\mathrm{S}$ phase.

\subsection{Loss of mitochondrial membrane potential $\left(\Delta \psi_{\mathrm{m}}\right)$ dependent apoptosis analysis}

Multiple death signals influence cell death during apoptosis. Mitochondrial dysfunction is an early event which regulates the production of ROS leading to apoptosis. $.^{83} \mathrm{Rh}-123$ examined the loss in mitochondrial membrane potential $\left(\Delta \psi_{\mathrm{m}}\right)$ in Hep-2 cells; the DAPI counterstained nucleus and the fluorescence images are shown in Fig. 7. A decrease in the mean fluorescence intensity clearly showed the $\Delta \psi_{\mathrm{m}}$ loss in the cells treated with $\mathrm{Au} / \mathrm{Ag}-1$ to 2 alloy and Ag@Au-3 to 8 core-shell for $24 \mathrm{~h}$. The observed fluorescence images clearly demonstrate that there is a loss in $\Delta \psi_{\mathrm{m}}$ due to the toxic effect of the synthesized $\mathrm{Au} / \mathrm{Ag}$ alloy and Ag@Au core-shell NPs, the uptake of rh-123 reflects the active mitochondria, whereas in the treated group the fluorescent intensity is significantly reduced when compared to the control group and the nucleus was stained by DAPI. ${ }^{\mathbf{4}}$ Overall, the results show that the induction of apoptosis in Hep2 cells was accompanied by alterations in $\Delta \psi_{\mathrm{m}}$. Several reports documented that drug-loaded NPs can effectively target cancer cells without any harm to healthy (non-cancerous) cells. ${ }^{\mathbf{8 5}, 86}$ These observations clearly state that the anti-proliferative effect of drug loaded NPs is a promising candidate to combat cancer.

\section{Conclusions}

In this report, Ag/Au alloy and Ag@Au core-shell NPs have been synthesized, and different techniques analyzed the structure, size and plasmonic properties of the NPs. By following the strategies of a novel preparation technique in this study, the synthesized alloys are monodispersed spherical, triangular, and hexagonal shaped, HRTEM and DLS determined the rodshaped particles and the average diameter. UV-visible spectroscopy, EDX, and HRTEM all show the alloy and core-shell NPs formation. The synthesized COCO gemini surfactant-Ag/Au alloy and Ag@Au core-shell NPs were observed to have high stability and biocompatibility in vitro systems. They are better stabilizers for the synthesis and stabilization of alloy and coreshell NPs in view of their structure and high charge density. COCO gemini surfactants are better for stabilizing alloy and core-shell NPs. Also, the synthesized core-shell NPs exhibited greater cytotoxicity to cancer cells than normal cells by inducing cell cycle arrest and cellular apoptosis. By comparing the obtained results from the in vitro studies, we anticipate that the developed core-shell NPs will prove to be active anti-cancer agents in a tumor-specific site in vivo. Further studies are required to confirm the response of anti-cancer and related mechanisms in a suitable in vivo model to elucidate their role in improved cancer chemotherapy and further applications such as photothermal therapy.

\section{Conflicts of interest}

There are no conflicts to declare.

\section{Acknowledgements}

Authors are thankful for the financial support from the Council of Scientific and Industrial Research (CSIR), New Delhi, India. One of the authors, A. M. Siddiq, is thankful to CSIR for providing financial support in the form of SRF. CSIR-CLRI Comm. No. 1292.

\section{References}

1 J. Huang, S. Vongehr, S. Tang, H. Lu, J. Shen and X. Meng, Langmuir, 2009, 25, 11890-11896.

2 Y. Mizukoshi, T. Fujimoto, Y. Nagata, R. Oshima and Y. Maeda, J. Phys. Chem. B, 2000, 104, 6028-6032.

3 N. Nishida, Y. Shiraishi, S. Kobayashi and N. Toshima, J. Phys. Chem. C, 2008, 112, 20284-20290.

4 Y.-S. Shon, G. B. Dawson, M. Porter and R. W. Murray, Langmuir, 2002, 18, 3880-3885.

5 A. V. Singh, B. M. Bandgar, M. Kasture, B. Prasad and M. Sastry, J. Mater. Chem., 2005, 15, 5115-5121.

6 Y. Yang, Y. Wang, S.-M. Jin, J. Xu, Z. Hou, J. Ren, K. Wang, E. Lee, L. Zhang and Y. Zhang, Mater. Chem. Front., 2019, 3, 209-215.

7 R. Jin, Y. C. Cao, E. Hao, G. S. Métraux, G. C. Schatz and C. A. Mirkin, Nature, 2003, 425, 487-490.

8 Y. Sun and Y. Xia, Science, 2002, 298, 2176-2179.

9 B. K. Jena and C. R. Raj, Langmuir, 2007, 23, 4064-4070.

10 J. Wu, Y. Qu, Q. Yu and H. Chen, Mater. Chem. Front., 2018, 2, 2175-2190.

11 Q. Zhang, J. Xie, J. Y. Lee, J. Zhang and C. Boothroyd, Small, 2008, 4, 1067-1071.

12 P. Selvakannan and M. Sastry, Chem. Commun., 2005, 16841686.

13 J. Yang, J. Y. Lee, H.-P. Too and S. Valiyaveettil, J. Phys. Chem. $B, 2006,110,125-129$.

14 M. S. Shore, J. Wang, A. C. Johnston-Peck, A. L. Oldenburg and J. B. Tracy, Small, 2011, 7, 230-234.

15 P. N. Njoki, M. E. Roots and M. M. Maye, ACS Appl. Nano Mater., 2018, 1, 5640-5645.

16 W. He, J. Cai, H. Zhang, L. Zhang, X. Zhang, J. Li and J.-J. Yin, ACS Appl. Nano Mater., 2018, 1, 222-231.

17 N. Cathcart, N. Murshid, P. Campbell and V. Kitaev, ACS Appl. Nano Mater., 2018, 1(11), 6514-6524.

18 Y. Ma, W. Li, E. C. Cho, Z. Li, T. Yu, J. Zeng, Z. Xie and Y. Xia, ACS Nano, 2010, 4, 6725-6734.

19 A. K. Samal, L. Polavarapu, S. Rodal-Cedeira, L. M. LizMarzán, J. Pérez-Juste and I. Pastoriza-Santos, Langmuir, 2013, 29, 15076-15082.

20 H.-L. Jiang, T. Akita, T. Ishida, M. Haruta and Q. Xu, J. Am. Chem. Soc., 2011, 133, 1304-1306.

21 T. Endo, K. Kerman, N. Nagatani, H. M. Hiepa, D.-K. Kim, Y. Yonezawa, K. Nakano and E. Tamiya, Anal. Chem., 2006, 78, 6465-6475.

22 H. Lai, F. Xu, Y. Zhang and L. Wang, J. Mater. Chem. B, 2018, 6, 4008-4028.

23 Z. Huang, A. Zhang, Q. Zhang and D. Cui, J. Mater. Chem. B, 2019, 7, 3755-3774. 
24 J. Cui, R. Jiang, C. Guo, X. Bai, S. Xu and L. Wang, J. Am. Chem. Soc., 2018, 140, 5890-5894.

25 D. Zhu, M. Liu, X. Liu, Y. Liu, P. N. Prasad and M. T. Swihart, J. Mater. Chem. B, 2017, 5, 4934-4942.

26 P. K. Jain, X. Huang, I. H. El-Sayed and M. A. El-Sayed, Plasmonics, 2007, 2, 107-118.

27 S. R. A. Rico, A. Z. Abbasi, G. Ribeiro, T. Ahmed, X. Y. Wu and D. de Oliveira Silva, Nanoscale, 2017, 9, 10701-10714.

28 S. Grade, J. Eberhard, J. Jakobi, A. Winkel, M. Stiesch and S. Barcikowski, Gold Bull., 2014, 47, 83-93.

29 D. Tiedemann, U. Taylor, C. Rehbock, J. Jakobi, S. Klein, W. A. Kues, S. Barcikowski and D. Rath, Analyst, 2014, 139, 931-942.

30 P. Mulvaney, Langmuir, 1996, 12, 788-800.

31 L. Braydich-Stolle, S. Hussain, J. J. Schlager and M.-C. Hofmann, Toxicol. Sci., 2005, 88, 412-419.

32 S. Hussain, K. Hess, J. Gearhart, K. Geiss and J. Schlager, Toxicol. in Vitro, 2005, 19, 975-983.

33 R. Foldbjerg, D. A. Dang and H. Autrup, Arch. Toxicol., 2011, 85, 743-750.

34 J. Conde, G. Doria and P. Baptista, J. Drug Delivery, 2012, 751075, 12.

35 H. J. Yen, S. h. Hsu and C. L. Tsai, Small, 2009, 5, 1553-1561. 36 V. Grasmik, C. Rurainsky, K. Loza, M. V. Evers, O. Prymak, M. Heggen, K. Tschulik and M. Epple, Chem.-Eur. J., 2018, 24, 9051-9060.

37 X. Sun, Y. Yang, Z. Zhang and D. Qin, Chem. Mater., 2017, 29, 4014-4021.

38 S. Hait and S. Moulik, Curr. Sci., 2002, 82, 1101-1111.

39 A. M. Siddiq, T. Parandhaman, A. F. Begam, S. K. Das and M. S. Alam, Enzyme Microb. Technol., 2016, 95, 118-127.

40 D. Li, W. Fang, H. Wang, C. Gao, R. Zhang and K. Cai, Ind. Eng. Chem. Res., 2013, 52, 8109-8113.

41 K. Esumi, J. Hara, N. Aihara, K. Usui and K. Torigoe, J. Colloid Interface Sci., 1998, 208, 578-581.

42 W. Wang, Y. Han, M. Gao and Y. Wang, CrystEngComm, 2013, 15, 2648-2656.

43 M. Antonietti and H. P. Hentze, Adv. Mater., 1996, 8, 840844.

44 M. Antonietti, C. Göltner and H.-P. Hentze, Langmuir, 1998, 14, 2670-2676.

45 K. Landfester, N. Bechthold, F. Tiarks and M. Antonietti, Macromolecules, 1999, 32, 2679-2683.

46 A. B. Páhi, Z. Király, Á. Mastalir, J. Dudás, S. Puskás and Á. Vágó, J. Phys. Chem. B, 2008, 112, 15320-15326.

47 Md. S. Alam, A. M. Siddiq, D. Natarajan, M. S. Kiran and G. Baskar, J. Mol. Liq., 2019, 273, 16-26.

48 S. Ristig, O. Prymak, K. Loza, M. Gocyla, W. Meyer-Zaika, M. Heggen, D. Raabe and M. Epple, J. Mater. Chem. B, 2015, 3, 4654-4662.

49 I. Lee, S. W. Han and K. Kim, Chem. Commun., 2001, 17821783.

50 G. C. Papavassiliou, J. Phys. F: Met. Phys., 1976, 6, L103.

51 M. P. Mallin and C. J. Murphy, Nano Lett., 2002, 2, 12351237.

52 S. Link, Z. L. Wang and M. El-Sayed, J. Phys. Chem. B, 1999, 103, 3529-3533.
53 S. Godipurge, S. Yallappa, N. J. Biradar, J. Biradar, B. Dhananjaya, G. Hegde, K. Jagadish and G. Hegde, Enzyme Microb. Technol., 2016, 95, 174-184.

54 H. Zhang, M. Okumura and N. Toshima, J. Phys. Chem. C, 2011, 115, 14883-14891.

55 I. Srnová-Šloufová, F. Lednický, A. Gemperle and J. Gemperlová, Langmuir, 2000, 16, 9928-9935.

56 D. Rana, D. Jamwal, A. Katoch, P. Thakur and S. Kalia, Analyst, 2016, 141, 2208-2217.

57 J. C. Love, L. A. Estroff, J. K. Kriebel, R. G. Nuzzo and G. M. Whitesides, Chem. Rev., 2005, 105, 1103-1170.

58 O. Magnussen, Chem. Rev., 2002, 102, 679-726.

59 E. Hutter and J. H. Fendler, Chem. Commun., 2002, 378-379. 60 M. G. Guzmán, J. Dille and S. Godet, Int. J. Chem. Biomol. Eng., 2009, 2, 104-111.

61 W. Lai, J. Zhou, Z. Jia, L. Petti and P. Mormile, J. Mater. Chem. C, 2015, 3, 9726-9733.

62 N. Tan, C. Lee and P. Li, Polymers, 2016, 8, 105.

63 C. Levard, E. M. Hotze, G. V. Lowry and G. E. Brown Jr, Environ. Sci. Technol., 2012, 46, 6900-6914.

64 B. B. Karakoçak, R. Raliya, J. T. Davis, S. Chavalmane, W.-N. Wang, N. Ravi and P. Biswas, Toxicol. In Vitro, 2016, 37, 61-69.

65 F. Xu, Q. Zhang and Z. Gao, Colloids Surf., A, 2013, 417, 201210.

66 K. Mallick, M. J. Witcomb and M. S. Scurrell, J. Nanopart. Res., 2007, 9, 323-330.

67 L. Zhang, X. Sun, Y. Song, X. Jiang, S. Dong and E. Wang, Langmuir, 2006, 22, 2838-2843.

68 J. Xu, X. Han, H. Liu and Y. Hu, J. Dispersion Sci. Technol., 2005, 26, 473-476.

69 M. S. Bakshi, J. Singh and G. Kaur, J. Colloid Interface Sci., 2005, 285, 403-412.

70 N. N. Kariuki, J. Luo, M. M. Maye, S. A. Hassan, T. Menard, H. R. Naslund, Y. Lin, C. Wang, M. H. Engelhard and C.-J. Zhong, Langmuir, 2004, 20, 11240-11246.

71 A. Monga and B. Pal, RSC Adv., 2015, 5, 39954-39963.

72 E. C. Dreaden, A. M. Alkilany, X. Huang, C. J. Murphy and M. A. El-Sayed, Chem. Soc. Rev., 2012, 41, 2740-2779.

73 H.-C. Huang, S. Barua, D. B. Kay and K. Rege, ACS Nano, 2009, 3, 2941-2952.

74 L.-C. Cheng, J.-H. Huang, H. M. Chen, T.-C. Lai, K.-Y. Yang, R.-S. Liu, M. Hsiao, C.-H. Chen, L.-J. Her and D. P. Tsai, J. Mater. Chem., 2012, 22, 2244-2253.

75 E. E. Connor, J. Mwamuka, A. Gole, C. J. Murphy and M. D. Wyatt, Small, 2005, 1, 325-327.

76 R. Shukla, V. Bansal, M. Chaudhary, A. Basu, R. R. Bhonde and M. Sastry, Langmuir, 2005, 21, 10644-10654.

77 D. F. Evans and H. Wennerström, The Colloidal Domain: Where Physics, Chemistry, Biology, and Technology Meet, Wiley, 2nd edn, 1999.

78 D. H. Napper, Polymeric stabilization of colloidal dispersions, Academic Pr, 1983.

79 J. Pietenpol and Z. Stewart, Toxicology, 2002, 181, 475-481. 80 K. Vermeulen, Z. N. Berneman and D. R. Van Bockstaele, Cell Proliferation, 2003, 36, 165-175. 
81 A. Basu and S. Haldar, Mol. Hum. Reprod., 1998, 4, 10991109.

82 A. Di Leonardo, S. H. Khan, S. P. Linke, V. Greco, G. Seidita and G. M. Wahl, Cancer Res., 1997, 57, 1013-1019.

83 D. R. Green and J. C. Reed, Science, 1998, 281, 1309-1312.

84 M. Karbowski, J. H. Spodnik, M.-a. Teranishi, M. Wozniak, Y. Nishizawa, J. Usukura and T. Wakabayashi, J. Cell Sci., 2001, 114, 281-291.
85 S. Mukherjee, M. Dasari, S. Priyamvada, R. Kotcherlakota, V. S. Bollu and C. R. Patra, J. Mater. Chem. B, 2015, 3, 3820-3830.

86 I. Rajendran, H. Dhandapani, R. Anantanarayanan and R. Rajaram, $R S C A d v$. , 2015, 5, 51055-51066. 